\title{
Application of MALDI Mass Spectrometry in Natural Products Analysis
}

Authors

Affiliations
Ricardo Silva ${ }^{1}$, Norberto Peporine Lopes ${ }^{1}$, Denise Brentan Silva ${ }^{1,2}$

${ }^{1}$ Núcleo de Pesquisa em Produtos Naturais e Sintéticos (NPPNS), Faculdade de Ciências Farmacêuticas de Ribeirão Preto, Universidade de São Paulo, Ribeirão Preto, SP, Brazil

${ }^{2}$ Laboratório de Produtos Naturais e Espectrometria de Massas (LAPNEM), Centro de Ciências Biológicas e da Saúde (CCBS), Universidade Federal de Mato Grosso do Sul (UFMS), Campo Grande, MS, Brazil

\author{
Key words \\ - MALDI \\ - dereplication \\ - natural products \\ - fragmentation \\ data processing
}

$\begin{array}{ll}\text { received } & \text { May } 3,2015 \\ \text { revised } & \text { March 1, 2016 }\end{array}$

accepted March 2, 2016

\section{Bibliography}

Dol http://dx.doi.org/

10.1055/s-0042-104800

Published online April 28, 2016

Planta Med 2016; 82: 671-689

(c) Georg Thieme Verlag KG

Stuttgart · New York .

ISSN 0032-0943

\section{Correspondence}

Norberto Peporine Lopes

Núcleo de Pesquisa em

Produtos Naturais e Sintéticos

(NPPNS)

Faculdade de Ciências Farma-

cêuticas de Ribeirão Preto

Universidade de São Paulo

Avenida do Café s/n

14040903 Ribeirão Preto, SP

Brazil

Phone: + 551636024168

Fax: + 551636024252

npelopes@fcfrp.usp.br

\section{Correspondence}

Denise Brentan Silva

Laboratório de Produtos

Naturais e Espectrometria

de Massas (LAPNEM)

Centro de Ciências Biológicas

e da Saúde (CCBS)

Universidade Federal de

Mato Grosso do Sul (UFMS)

Avenida Costa e Silva s/n

79070-900 Campo Grande MS

Brazil

Phone: + 556733457366

Fax: + 556733457366

denise.brentan@ufms.br

\section{Abstract}

$\nabla$

This article presents the utility of mass spectrometry with a MALDI ionization source in natural products analysis. The advantages and drawbacks of this technique for natural products analyses will be presented and discussed. In addition, the structural determination of secondary metabolites using MALDI-MS/MS will be explored, which can guide MALDI experimental methods and stimulate new research in this area. Finally, several important approaches for MALDI data processing will be discussed.

$\begin{array}{ll}\text { Abbreviations } \\ \text { 4NA: } & \text { 4-nitroaniline } \\ \text { 9-AA: } & \begin{array}{l}\text { 9-aminoacridine } \\ \text { atmospheric pressure chemical ioniza- } \\ \text { APCI: }\end{array} \\ \text { tion } \\ \text { CHCA: } & \alpha \text {-cyano-4-hydroxycinnamic acid } \\ \text { CID: } & \begin{array}{l}\text { collision induced disassociation } \\ \text { DAN: }\end{array}\end{array}$

\section{Introduction}

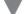

In the late 1950s, Roland Gohlke and Fred McLafferty hyphenated an EI mass spectrometer as the detector in gas chromatography [1], which had a tremendous influence on natural products chemistry. The impact of this innovation can be measured by the number of reviews written during the 1960s about the application of mass spectrometry in natural products analysis. In the same period, another technique based on laser desorption/ionization mass spectrometry appeared and was applied to the ionization of organic molecules by irradiation with a high-intensity laser pulse. This method had a lower impact on the natural products research than electron ionization be-
DHAP: 2,5-dihydroxyacetophenone

DHB: 2,5-dihydroxybenzoic acid

DIT: dithranol

EI: electron ionization

FAB: fast atom bombardment

FT: $\quad$ Fourier transform

IAA: trans-3-indoleacrylic acid

ICR: ion cyclotron resonance

IMS: imaging mass spectrometry

IT: $\quad$ ion trap

LDI: laser desorption/ionization

LiDHB: lithium 2,4-dihydroxybenzoate

HABA: 2-(4-hydroxyphenylazo)benzoic acid

MALDI: matrix-assisted laser desorption/ionization

NALDI: nanostructure-assisted laser desorption/ionization

PSD: $\quad$ post source decay

Q: $\quad$ quadrupole

ReTOF: reflectron time-of-flight

SA: $\quad$ sinapinic acid

SELDI: surface-enhanced laser desorption/ ionization

THAP: 2,4,6-trihydroxyacetophenone

tween 1950 and 1970. Research by Michael Karas and Franz Hillenkamp led to the new and alternative use of a matrix in the laser ionization process in 1987 [2]. The authors demonstrated the application of MALDI in the analysis of high-molar mass compounds by the combination of the analyte's solubilization in an organic matrix and its excitation by a laser. In this process, the matrix must have a strong absorbance at a specific wavelength and must be easily sublimated [3]. Ionization generally occurs through acid-base reactions (protonation and deprotonation) of the analyte and the matrix in a hot plume of ablated gases, but coordination and oxidation reactions may also occur $[3,4]$. Considering the chemical properties of the matrix, the initial studies were dedi- 


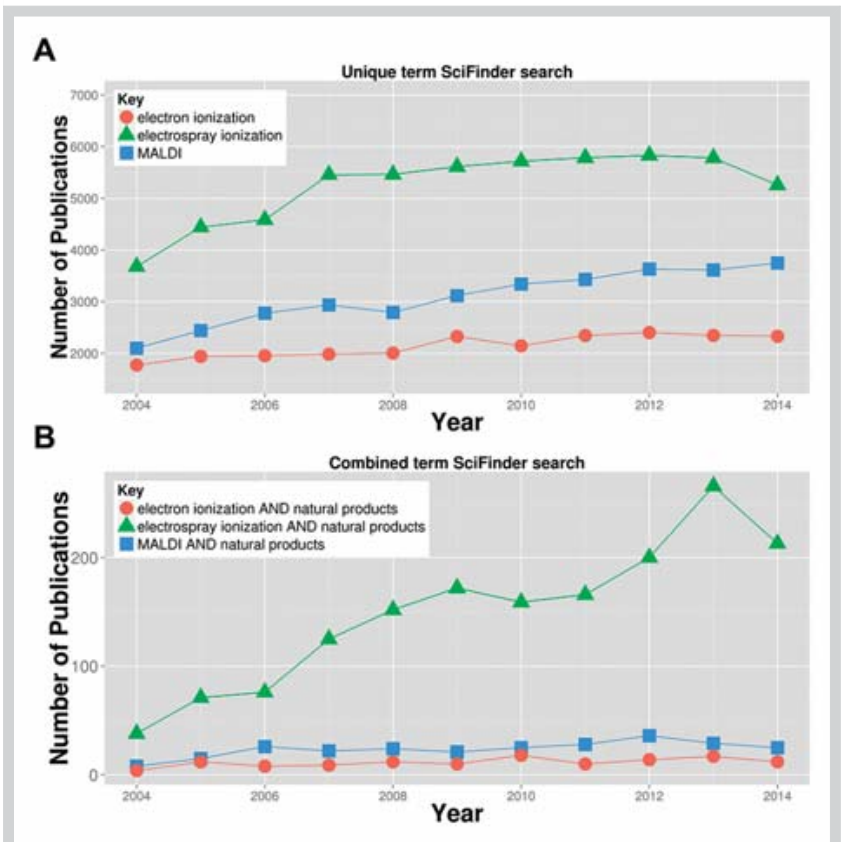

Fig. 1 Bibliographic search in Chemical Abstracts Service (CAS) by SciFinder Scholar. The terms electron ionization (EI), electrospray ionization (ESI), and matrix-assisted laser desorption/ionization (MALDI) were used as keywords in the search in a first step (A), and they were refined with the term natural products in a second step (B). (Color figure available online only.)

cated to biomolecules (DNA, proteins, peptides, sugars, and others), with few applications in natural products chemistry.

In 2006, Crotti and coworkers published a review that compared the growth of several ionization processes from 1992 to 2004 [5]. At that time, ESI was greatly increasing, and the total number of published studies using ESI was twice the number of those using MALDI in 1994. The use of EI was largely constant during the analysis period, which is likely due to the requirement of thermostability and volatilization of the analytes. Natural products chemistry was responsible for only $5 \%$ of all mass spectrometry publications, and the majority of them were related to ESI [5]. An update on the impact of ESI, EI, and MALDI ionization techniques on natural products chemistry is shown in $\bullet$ Fig. 1. The bibliographic search was of the Chemical Abstracts Service (CAS) by SciFinder Scholar (March 13th, 2015) using MALDI, ESI, and EI ionization as keywords in the first step ( Fig. 1 A). ESI applications increased from 2004 to 2008, but the number of articles remained at approximately 5000 publications per year from 2008 to 2014. EI exhibited a slight increase compared with the previous compilation [5] but remained constant at approximately 2500 publications per year. Conversely, MALDI publications increased annually, and no stabilization was observed (० Fig. 1 A).

The bibliographic search refined with the term natural products in the second step showed another behavior ( Fig. 1 B). ESI is still growing, but MALDI remains constant, similar to EI. This trend likely reflects the enormous expansion of metabolomics studies, which utilizes ESI [6], and the limited knowledge or perspective of MALDI in natural products investigations. The same effect can be observed in a recent volume of Natural Products Reports that was dedicated to the mass spectrometry of natural products, coordinated by Pieter Dorrestein [7]. This report discussed the applications and advances in the instruments, the im- proved experimental workflows, and the important mass spectrometry tools from the perceptive of increased performance of structural elucidation and natural products functional characterization. The majority of publications were focused on new perspectives of ESI and other atmospheric pressure ionization processes in addition to the well-established use of EI. MALDI was only highlighted in tissue imaging studies applications [8-10], thus confirming the tendency of uses previously discussed and presented in 0 Fig. 1. Outside the reduced focus on the MALDI application, various successful studies have been published on the application of MALDI-MS in natural products analysis, which will be discussed throughout this article. Therefore, significant and exciting progress in MALDI-MS natural products applications is expected in the coming years.

\section{MALDI-MS Analyses of Natural Products}

$\boldsymbol{\nabla}$

\section{MALDI technique}

MALDI is a soft ionization technique initially developed for macromolecule analyses, which is greatly expanding due to its advantages, although more research is required to understand the processes involved, primarily the reactions in the ionization steps and fragmentation, especially for methods with a high energy transfer [11-13]. Basically, the ionization processes in MALDI can be explained through three basic steps: 1) the incorporation and isolation of analytes in a matrix, 2) the excitation of the matrix producing the plume by physics desorption/ablation, and 3 ) the ionization of the analytes by ion-molecules reactions [11-13]. There are different models that try to explain the MALDI ionization process, but they are crude, and no method is universally accepted. One widely discussed model is the cluster model, originally called the "lucky survivors" model. One common agreement is the function of the matrix, which includes the isolation of analyte molecules, the absorption of laser energy, the co-desorption of analytes and the charge transfer. In addition, the matrix can be useful to protect the analyte molecules, reducing their in-source dissociations [3].

After laser energy deposition, photons from the laser are absorbed by the matrix molecules and a conversion of most of the energy to heat occurs. Subsequently, the matrix-analyte solid disintegrates and a plume is produced, in which the secondary chemical reactions occur, promoting the ionization of the analytes by charge transfer. It can be of three types: proton, electron, and cation transfer. These ion-molecule reactions happen in the plume and they are reduced significantly with the plume expansion, thus the secondary reactions did not run to completion and many matrix ions are not neutralized, being observed in the spectra. The high-plume density is an important parameter to increase the secondary reactions and to reduce the matrix ions in the spectra. It can be targeted by a higher laser fluence (related to the concentration of primary ions) [3,11-13]. Besides laser intensity, the secondary plume reactions can be additionally controlled by analyte concentration and matrix choice $[3,11,12]$.

The matrix excitation occurs electronically by ultraviolet lasers or vibrational stages by infrared lasers. And there are different kind of used lasers in MALDI, such as nitrogen, $\mathrm{Nd}$ :YAG, $\mathrm{CO}_{2}, \mathrm{Er}$ :YAG, $\mathrm{ArF}, \mathrm{KrF}$, and others. The lasers work using different wavelengths and amount of single-photon energy that influences the ionization efficiency, mainly for LDI analyses (without matrix). The most common lasers are nitrogen (337 nm, single-photon energy of $3.6 \mathrm{~V}$ ) and frequency-tripled Nd:YAG (355 nm, single-photon 
energy of $3.3 \mathrm{~V}$ ). Different to the nitrogen laser, Nd:YAG has a higher laser frequency, enabling very fast data acquisition, and the Gaussian energy profile (not equally distributed) that could represent some problems of sensitivity and resolution. However, a modified Nd:YAG laser was developed without this disadvantage, showing a well-structured energy profile [13-15].

Moreover, the choice of mass analyzer is an important decision to get good results according its specific features, which include the following: resolution, mass accuracy, mass range extension, sensitivity, dynamic range, quantification, speed, and handling. The most common analyzers applied for MALDI are IT, quadrupole (Q), Orbitrap, FT-ICR, and TOF, and there also are hybrid mass spectrometers from these analyzers. As important reviews and books have described the analyzers $[6,16,17]$, an extensive description is not shown here, and only the special applications in the area are reported. In addition, there are mass spectrometers coupled to ion mobility spectrometry; an electrophoretic technique that separates the ions based on their mobilities in the gas phase, allowing the chemical study of conformations, separation of isomers, and isobars ions. The ion mobility spectrometry is a theme of many review articles, describing the mass spectrometers available, their advantages, and disadvantages $[18,19]$.

Different conventional matrices have been used for several purposes, such as DHB, CHCA, DHAP, SA, 4NA, THAP, nicotinic acid, picolinic acid, ferulic acid, and others, but few matrices were well characterized and many points are still unclear, for example, a deep explanation about their efficiencies, the chemical species produced in the plume for each matrix, and the information about the physics and chemistry properties of plume expansion and reactions $[12,20]$. The good features for matrices are linked to their solubility, absorptivity, reactivity, volatility, and desorption and a considerable number of reports provide details on preparation methods of different matrices, which includes dried droplet, crushed crystal, fast evaporation, overlayer method, spin coating, and electrospray [20]. Some matrices have known applications, such as for oligonucleotides, proteins, lipids, polymers, and carbohydrates ( Table 1), while indication guides for specific natural product classes have not been reported [11] that stimulates more studies in this area, since there are innumerous advantages of MALDI (described on next item). The main analyses of natural products by MALDI, including the applied matrices, are summarized in 0 Tables $\mathbf{1}$ and $\mathbf{2}$. Another important point for choice matrix is variable amounts of energy are transferred to analytes, which depends on the matrix and can represent different effects on ion fragmentation due to changes of their internal energy [21], but these effects are underexplored, mainly for natural products.

LDI analyses without a matrix have also been described, mainly for conjugated compounds, which is possible for ionization without a matrix since they can absorb the laser radiation. Some natural products were already analyzed by LDI, such as flavonoids and carotenoids, but the role of the matrix is fundamental in reducing the in-source dissociation as well as increasing the efficiency of ionization and thereby increasing sensitivity [22,23], as confirmed in the investigation of ionization and in-source dissociation of twenty-six flavonoids [22] and others studies (section Application - for more examples and details).

\section{Drawbacks and advantages}

The main disadvantages reported for MALDI analyses include the background matrix ions, which are observed in the mass range used for small compounds (<1000 Da), the possibility of sample photodegradation, the in-source dissociations of analytes, and the difficulty in working on line with liquid chromatography, which is not yet commonly applied but yields additional information about isomers $[6,11]$. Some alternatives have been described to reduce this background, for example, carbon nanotubes, ionic liquids, graphene, surfactants with traditional matrices, and a low proportion of matrix (matrix: analyte) [24-26]. In addition, there have been great efforts to reduce the fragmentation of analytes in the source [22]. This information is relevant for improving MALDI results and applications in many study areas, such as metabolomics, dereplication, quantification, biological fingerprinting analyses, and IMS, stimulating its utility in natural products research. The low reproducibility is another drawback already reported, but several approaches have been described to improve it, many of which are related to crystal homogeneity in different matrices, sample preparation methods, and/or increasing the number of runs per sample [24,26-30]. The methods to improve the cocrystallization of the analyte-matrix mixture include procedures such as fast evaporation preparation, electrospray sample deposition, and others [6, 26,31,32]. So MALDI has also been successfully applied to quantitative studies for alkaloids [33-35], anthocyanins [36-38], flavonoids [39], acetogenins [40], spirolides [41], curcuminoids [42], and rotenoids [43].

From new technologies overcoming the bottlenecks of MALDI analyses, the scientific community can have access to all its benefits and the application of it can be enlarged in the natural products area, mainly because the MALDI technique exhibits several advantages. They include the ability to analyze complex mixtures with less ion suppression compared to ESI, high sensitivity, high tolerance of salts and contaminants, low sample consumption, high throughput, simple and rapid sample preparation, low time consumption to obtain the spectra ( $\approx 60 \mathrm{~s}$ ), and the production of singly charged species $[6,27]$.

\section{Applications}

MALDI-MS has been applied to determine the molecular weight of some natural products, to identify the chemical structures, as well as for metabolomic studies, quantification and others, however, recently it has also been used to establish tissue distribution of the metabolites by MALDI imaging [6, 25, 27,31] ( $\bullet$ Fig. 2).

Although there are several applications of MALDI in natural products chemistry, the higher number of published articles is related to its use for molecular weight determination by low or high resolution. Several glycosylated and non-glycosylated secondary metabolites have been analyzed, such as hydrolysable and condensed tannins, anthocyanins, alkaloids, flavonoids, saponins, rotenoids, carotenoids, xanthophylls, glycosylated triterpenes, theaflavins, thearubigins, phenolics, sesquiterpene lactones, steroids, diterpenes, sesterterpenes, cyanogenic glycosides, and others (- Fig. 3, Table 2) [22,23,36,37,44-49], demonstrating its huge applicability and ability to analyze secondary metabolites. Among glycosides analyzed by MALDI-MS from the period 1999 to 2010 [44-49], saponins, steroids, triterpenes, and flavonoids are the glycosylated metabolites predominantly described ( Fig. 4).

New studies have shown successful applications of MALDI for metabolic profiling in comparison to other techniques $[27,50$, 51], for example, the analyses of fractions from Psoralea corylifolia L. (Fabaceae). They were analyzed by different analytical methods, such as LC-DAD, LC-APCI-MS, and MALDI-TOF MS, with the use of oxidized carbon nanotubes as the matrix. The LC-APCIMS increased the number of detected substances compared to 
Table 1 Typical commercial MALDI matrices and their applications and characteristics.

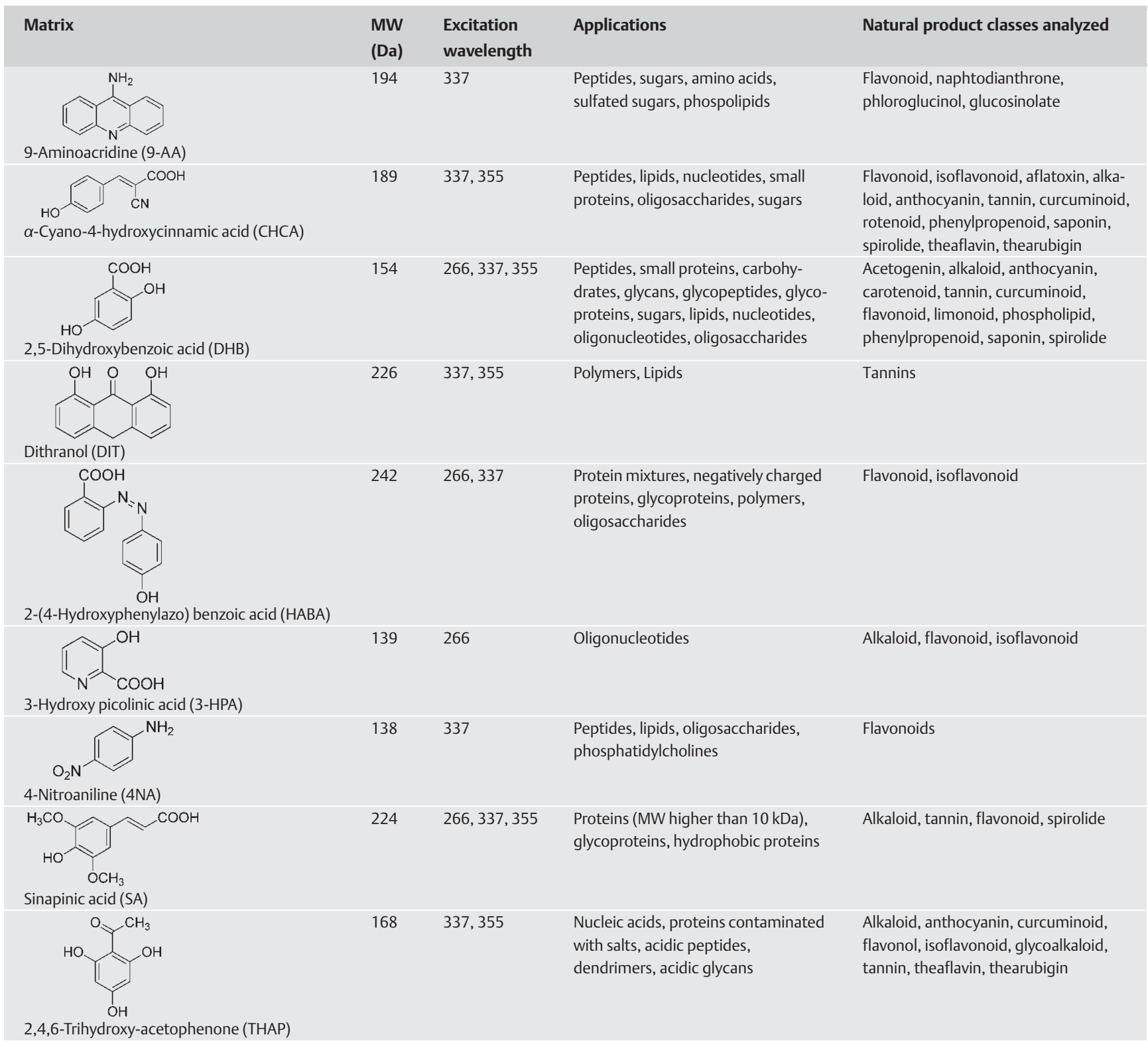

MW: molecular weight

the UV detector because some peaks were observed only by APCI-MS and coeluting peaks could be identified. MALDI-TOF MS showed a high ability to detect the substances, even without previous chromatographic separation, and with sensitivity for low mass substances. In this study, a total of 188 components were identified from enriched fractions using all the techniques, $65 \%$ of all identified components could be identified by MALDI, and almost $50 \%$ of them were identified only by MALDI analyses [50]. This superiority of MALDI for metabolic profiling studies compared with LC-ESI-MS was also verified from analyses of Balanites aegyptiaca (L.) Del. (Zygophyllaceae) extracts and the identification of additional saponins was only observed by MALDI analyses [51]. Thus, the clear superiority for the detection and identification of compounds in a complex sample has been confirmed for it. Other interesting MALDI applications include structural identification, chemical screening, single plant cell analyses, molecular interactions with target molecules, and the determination of the identity of medicinal plants.
Although the technique shows some drawbacks for quantification studies, Wang and collaborators [36] compared the quantification by HPLC-DAD and MALDI-TOF MS of glycosylated anthocyanins ( Fig. 5A) and demonstrated the substantial potential of high-throughput MALDI quantification. The MALDI technique proved to be faster at accurately identifying and quantifying the anthocyanins; therefore, MALDI-TOF is a faster alternative to HPLC analyses. In addition, the quantification of glycosylated flavonols ( Fig. 5B) by MALDI-TOF MS was also highly correlated with the results obtained by HPLC-UV, which indicates that MALDI-TOF is a valid system for these evaluations [39]. The important tools for quantification by MALDI are the high repetition rate laser, which improves precision and sensitivity, and the use of an internal standard to average out variations in instrument response. Ideally, the internal standards must be chemically similar to the target substances, and the best approach is the use of the same target substance that is isotopically labeled $[31,52,53]$. 
Table 2 MALDI MS applications for examination of natural products.

\begin{tabular}{|c|c|c|c|c|}
\hline Classes of natural products & Source & Matrix & Study goal & Ref. \\
\hline Acetogenins & Annona muricata & DHB & Quantification & {$[40]$} \\
\hline Aflatoxins & Peanuts & $\mathrm{CHCA}$ & Screening & {$[63]$} \\
\hline Alkaloid & Urine & CHCA, DHB & Quantification & [35] \\
\hline Alkaloids & $\begin{array}{l}\text { Corydalis yanhusuo, Coptis chinensis and } \\
\text { Aconitum Carmichaeli }\end{array}$ & CHCA and DHB & Metabolite profiling and identification & {$[56]$} \\
\hline Alkaloids & Aconitum carmichaeli & $\mathrm{SA}, \mathrm{DHB}$ and CHCA & Metabolite profiling and quantification & [57] \\
\hline Alkaloids & Strychnos nux-vomica & $\begin{array}{l}\text { SA, THAP, 3-aminoquino- } \\
\text { line (3-AMQ), 3-hydroxy } \\
\text { picolinic acid (3-HPA), } \\
\text { CHCA and DHB }\end{array}$ & Metabolite profiling & [58] \\
\hline Alkaloids & Sinomenium acutum & CHCA, SA, and DHB & $\begin{array}{l}\text { Identification and differentiation of } \\
\text { herbal samples }\end{array}$ & {$[60]$} \\
\hline Alkaloids & Berberis baradana & Matrix-free & Identification & {$[80]$} \\
\hline Amino acid & Solanum melongena & $\mathrm{DHB}$ & Spatial analysis* & [109] \\
\hline Anthocyanins & Vaccinium corymbosum & THAP & $\begin{array}{l}\text { Identification and quantification (com- } \\
\text { parison between HPLC and MALDI) }\end{array}$ & [36] \\
\hline Anthocyanins & Red wine, fruit juice, and syrup & THAP & Identification and quantification & [37] \\
\hline Anthocyanins & Arabidopsis thaliana & $\begin{array}{l}\text { caffeic acid (CAF), ferulic acid } \\
\text { (FER), DHB, CHCA and THAP }\end{array}$ & Quantification & [38] \\
\hline Anthocyanins & Oryza sativa & DHB & Identification and spatial analysis* & [168] \\
\hline Carotenoids & $\begin{array}{l}\text { Lycopersicon esculentum, Arabidopsis } \\
\text { thaliana and Capsicum species }\end{array}$ & DHB & Metabolite profiling and identification & {$[64]$} \\
\hline Carotenoids & Citrus reticulata and Citrus sinensis & DHB & Profiling and identification* & [136] \\
\hline Condensed tannins & Pinus pinaster and Pinus radiata & DHB & Profiling and identification & [65] \\
\hline Condensed tannins & $\begin{array}{l}\text { Salix alba, Picea abies, Tilia cordata and } \\
\text { Fagus sylvatica }\end{array}$ & $\begin{array}{l}\text { CHCA, SA, DIT, } 3-\beta \text {-indole } \\
\text { acrylic acid (IAA) and DHB }\end{array}$ & $\begin{array}{l}\text { Metabolite profiling and identifica- } \\
\text { tion* }\end{array}$ & {$[66]$} \\
\hline Condensed tannins & Quebracho wood, mimosa, and cacao & DHB & Fragmentation study* & [128] \\
\hline Condensed tannins & Theobroma cacao & DHB & Identification and fragmentation study* & [153] \\
\hline Condensed tannins & Cinnamomum zeylanicum & $\mathrm{DHB}$ & Identification* & [154] \\
\hline Condensed tannins & Eugenia dysenterica & DHB & Identification* & [155] \\
\hline Condensed tannins & $\begin{array}{l}\text { Anadenanthera colubrina, Commiphora } \\
\text { leptophloeos and Myracrodruon urundeuva }\end{array}$ & DHB & Identification* & [156] \\
\hline Condensed tannins & Pityrocarpa moniliformis & DHB & Identification* & [157] \\
\hline Condensed tannins & Prunus dulcis & DHB & Qualitative profiling and identification* & [158] \\
\hline Curcuminoids (diarylheptanoid) & Curcuma longa & CHCA, DHB and THAP & Detection and quantification & [42] \\
\hline Diverse classes & Psoralea corylifolia & oxidized carbon nanotubes & Identification & {$[50]$} \\
\hline Flavonoids & Onion and green tea & THAP, HABA, DHB, and CHCA & Targeted analysis and identification* & {$[68]$} \\
\hline Flavonoids & Lychnophora species & Matrix-free & Identification and spatial analysis* & [74] \\
\hline Flavonoids & Apple (delicious golden) & CHCA and DHB & Spatial analysis & [96] \\
\hline Flavonoids & Purified compounds & CHCA and DHB & Fragmentation studies* & [122] \\
\hline Flavonoids & Isolated standards & $\mathrm{DHB}$ & Ion Cluster formation studies* & [124] \\
\hline Flavonoids & Isolated standards & $\begin{array}{l}\text { CHCA, DHB, 4NA, vanillin } \\
\text { (VAN), nicotinic acid (NI), } \\
\text { SA, SAM, LiDHB and NALDI }\end{array}$ & $\begin{array}{l}\text { Ionization and in-source dissociation } \\
\text { mechanisms* }\end{array}$ & [22] \\
\hline Flavonoids & Isolated standards & Norharman & $\begin{array}{l}\text { Fragmentation and in-source dissocia- } \\
\text { tion studies* }\end{array}$ & [125] \\
\hline $\begin{array}{l}\text { Flavonoids, fatty acids, and } \\
\text { others }\end{array}$ & $\begin{array}{l}\text { Arabidopsis thaliana, Drosophila mela- } \\
\text { nogaster, Acyrthosiphon pisum }\end{array}$ & $\begin{array}{l}\text { 1,8-bis(dimethylamino) } \\
\text { naphthalene (DMAN) }\end{array}$ & Targeted analysis and identification & [72] \\
\hline $\begin{array}{l}\text { Flavonoids, naphtodianthrones } \\
\text { and phloroglucinols }\end{array}$ & Arabidopsis thaliana and Hypericum species & 9-AA & Spatial analysis & [107] \\
\hline Flavonols & Prunus dulcis & THAP & Identification and quantification & [39] \\
\hline Glucosinolates & Arabidopsis thaliana & 9-AA & Spatial analysis & [106] \\
\hline Glycoalkaloids & Solanum tuberosum & THAP & Quantification & [34] \\
\hline Hydrolysable tannins & Chinese gall & DHB, THAP, and CHCA & Identification* & [59] \\
\hline Hydrolysable tannins & $\begin{array}{l}\text { Castanea sativa, Caesalpinia spinosa, Quer- } \\
\text { cus infectoria (galls) }\end{array}$ & DHB & Fragmentation study* & [137] \\
\hline Hydrolysable tannins & Rosa chinensis & Matrix-free & Identification* & [159] \\
\hline Hydrolysable tannins & Mangifera indica & $\mathrm{DHB}$ & Identification* & [160] \\
\hline Hydrolysable tannins & Purified compounds & DHB & $\begin{array}{l}\text { Identification and evaluation of cat- } \\
\text { ionization reagents* }\end{array}$ & [161] \\
\hline Hydrolysable tannins & $\begin{array}{l}\text { Astronium urundeuva and Astronium } \\
\text { graveolens }\end{array}$ & DHB & Identification* & [162] \\
\hline Isoflavonoids & Soy beans & HCCA, THAP, DHB, HABA & Targeted analysis and identiification* & [135] \\
\hline Limonoids & Azadirachta indica and Melia azedarach & DHB & Detection and identification & [207] \\
\hline Lipids & Saccharomyces cerevisiae & DHB & Targeted analysis and identification & {$[67]$} \\
\hline
\end{tabular}


Table 2 MALDI MS applications for examination of natural products. continued

\begin{tabular}{|c|c|c|c|c|}
\hline Classes of natural products & Source & Matrix & Study goal & Ref. \\
\hline Lipids & Isolated standards & $\mathrm{DHB}$ & Fragmentation study* & [138] \\
\hline $\begin{array}{l}\text { Phenylpropenoid and } \\
\text { flavonoids }\end{array}$ & $\begin{array}{l}\text { Scutellaria barbata, Angelica sinensis and } \\
\text { Scutellaria baicalensis }\end{array}$ & $\begin{array}{l}\text { CHCA, DHB, graphene and } \\
\text { graphene oxide }\end{array}$ & $\begin{array}{l}\text { Metabolite profiling and ionization } \\
\text { studies* }\end{array}$ & {$[25]$} \\
\hline Phenolics & Different Lichen species & Matrix-free & Dereplication studies & [208] \\
\hline Phospholipids & Egg yolk & $\mathrm{DHB}$ & Identification & [77] \\
\hline Polyphenols & $\begin{array}{l}\text { cranberry, grape, sorghum, and } \\
\text { pomegranate }\end{array}$ & $\mathrm{IAA}$ & Identification* & [163] \\
\hline Quaternary alkaloids & Corydalis yanhusuo (rhizoma) & $\mathrm{DHB}$ & Identification and quantification* & [33] \\
\hline Rotenoids & Brassica napus & CHCA & Quantification* & [43] \\
\hline Saponins & Balanites aegyptiaca & $\mathrm{DHB}$ & Metabolite profiling & [51] \\
\hline Saponins & Panax ginseng and Panax quinquefolius & CHCA, SA and DHB & $\begin{array}{l}\text { Identification and differentiation } \\
\text { of the species* }\end{array}$ & {$[55]$} \\
\hline Saponins & Bacopa monnieri & CHCA & Comparison of methods and identification & [134] \\
\hline Saponins & Quillaja saponaria & DHB & Targeted analysis* & [146] \\
\hline Saponins & Holothuria forskali & $\mathrm{CHCA}$ & Identification and spatial analysis* & [147] \\
\hline Saponins & Holothuria lessoni & CHCA & Structural elucidation* & $\begin{array}{l}{[150,} \\
151]\end{array}$ \\
\hline Saponins and triterpenes & Centella asiatica & CHCA & Identification & [78] \\
\hline Spirolides & Phytoplankton & CHCA, DHB, and SA & Identification and quantification* & [41] \\
\hline Steroidal lactones and alkaloid & Withania somnifera and Nicotiana tabacum & Matrix free & Screening* & {$[62]$} \\
\hline Steroids and lipopeptides & Standards & Coumarins & Evaluation of matrix efficiency & [209] \\
\hline Theaflavins, thearubigins & Yunnan black tea & THAP, CHCA & Identification & [169] \\
\hline $\begin{array}{l}\text { Thearubigins and flavan-3-ol } \\
\text { derivatives }\end{array}$ & Black tea leaves & DHAP & Structural elucidation & [170] \\
\hline Undermined & Echinacea species & CHCA, SA & $\begin{array}{l}\text { Metabolite profiles, differentiation of } \\
\text { species }\end{array}$ & {$[61]$} \\
\hline
\end{tabular}

* Based on MS/MS data

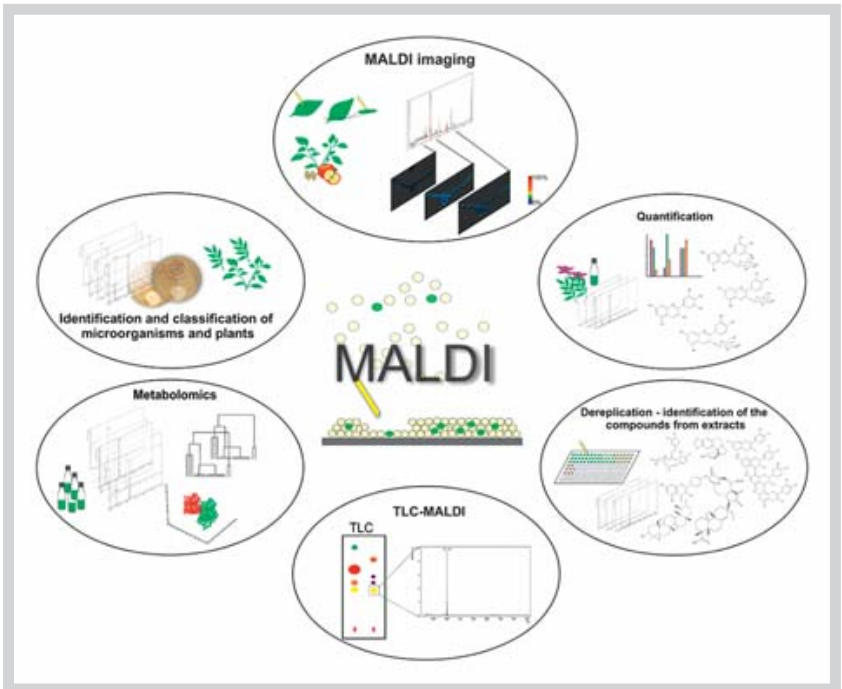

Fig. 2 Some applications of MALDI in natural products. (Color figure available online only.)

In addition, MALDI-MS has also been applied to identify and classify microorganisms based on proteomic fingerprints [54]. This strategy was demonstrated by Ernst and collaborators [27] upon examination of low mass ( $<1200 \mathrm{Da}$ ) metabolites, but using plant extracts. In this paper, the first protocol for creating a metabolic fingerprint of plants by MALDI-TOF MS was proposed. Three different MALDI matrices and subsequent multivariate data analysis by in-house algorithms implemented in the R environment were employed to taxonomically classify plants from different genera,

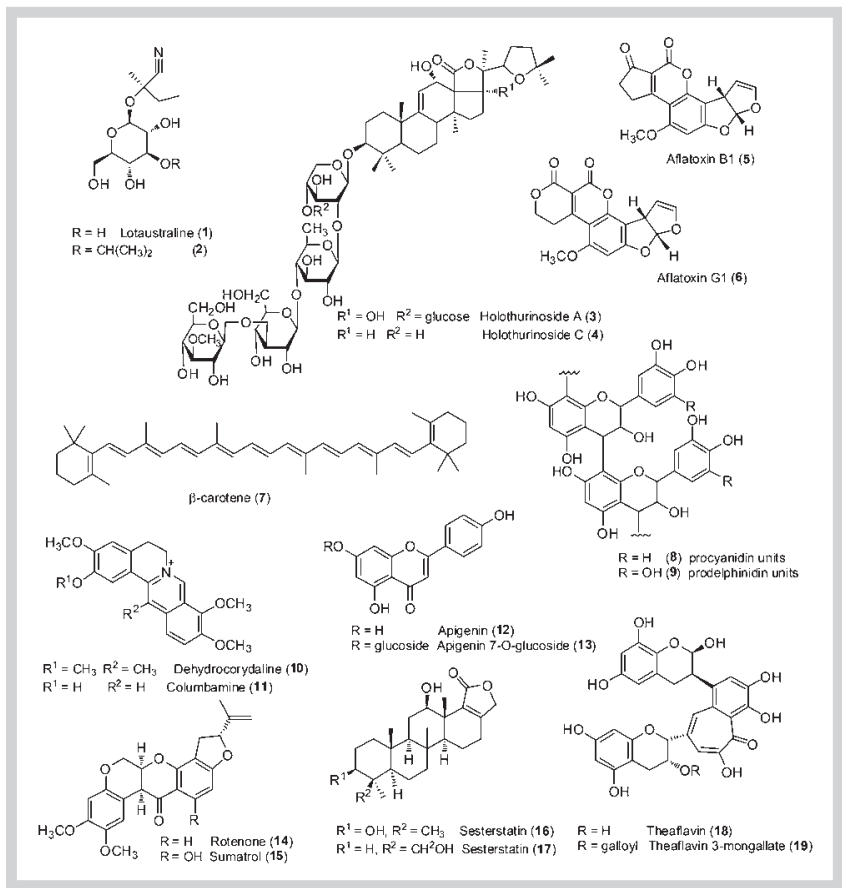

Fig. 3 Some examples of natural products analyzed by MALDI: cyanogenic glycosides $(\mathbf{1}, \mathbf{2})$, triterpenoid saponins $(3,4)$, aflatoxins $(5,6)$, carotenoid (7), flavones $(12,13)$, typical linear condensed tannins possessing B-type linkage $(\mathbf{8}, \mathbf{9})$, rotenoids $(\mathbf{1 4}, \mathbf{1 5})$, sesterterpenes $(\mathbf{1 6}, \mathbf{1 7})$, and theaflavins $(18,19)$. 
families, and orders. Initially, analyses without or with only one matrix were performed, but the results did not provide sufficient chemical information to correctly classify the plants. Then, several matrices were evaluated to select the best matrices that yield a higher number of ionized compounds and have less dissociation in the source in both ion modes. 4NA and CHCA matrices were selected for negative and positive ion modes, respectively. However, the nonpolar compounds, such as some triterpenes and diterpenes, were not ionized using these common matrices, and they could only be ionized with the LiDHB matrix, a synthesized matrix. Thus, the chemical information from plant extracts was enlarged with the nonpolar compounds that, using careful algorithms and parameter selections, allowed a close taxonomic classification with $92 \%$ similarity to the taxonomic classifications found in the literature [27].

Recently, another relevant MALDI-MS application was reported to identify different plants. It was also successfully used to differentiate the herbs Panax ginseng C. A. Meyer and Panax. quinquefolium L. (Araliaceae) because they have similar chemical and physical properties, including a problematic botanic differentiation, but with substantially different therapeutic effects that highlight the importance of a correct identification. The methodology allowed the unambiguous differentiation between the two species, required a small quantity of material, and was fast, robust, and simple [55]. Consequently, MALDI-MS can potentially characterize adulterants within the plants and perform rapid dereplication and quantification studies. The characterization of medicinal plants by MALDI-MS has been described for other plants, such as for the species Aconitum carmichaeli Debx. (Ranunculaceae), Corydalis yanhusuo W.T.Wang (Papaveraceae), Echinacea species (Asteraceae), and others [56-61]. MALDI can also be applied directly to the analysis of the powdered plant material [62], representing an important tool for quality control, since secondary metabolites have been successfully screened by MALDI-MS, such as aflatoxins [63], saponins [51], anthocyanins $[36,37]$, carotenoids [64], tannins [59,65,66], lipids and phospholipids [67], flavonoids [68], and others (० Fig. 4). In general, metabolomics studies can be obtained by MALDI-MS directly from extracts, tissue, or single cells [6,69-72], which highlights the potential to define the tissue distribution of the metabolites by MALDI imaging [73-75]. This application is extremely useful in metabolomics, representing a promising future in studies such as metabolic compartmentalization $[6,69,70]$ (see MALDI imaging section below).

Another promising methodology is TLC combined directly with MALDI-MS to identify compounds. The TLC is an easy and fast technique to separate compound mixtures and it is widely used in natural products laboratories, facilitating its implementation for this purpose [76]. TLC-MALDI MS has been applied to analyze phospholipids from chicken eggs [77], centellosides from Centella asiatica (L.) Urb. (Apiaceae) [78], siderophores from microbial samples [79], and alkaloids from Berberis barandana S. Vid. (Berberidaceae) [80]. Despite the advantages of TLC-MALDI MS, such as low cost for chromatographic separation, low time consumed, and direct analysis (without the extraction from TLC), its use has been restricted to natural products chemistry due to the yet low expansion of the technique [76].

The TLC-LDI-MS (analysis without the matrix) was applied to the analysis of quaternary protoberberine alkaloids from B. baranda$n a(\odot$ Fig. $6 \mathrm{~A})$. The compounds suffered in-source dissociations [80], which were likely intensified due to the matrix absence; therefore, more studies are required to understand the matrix role

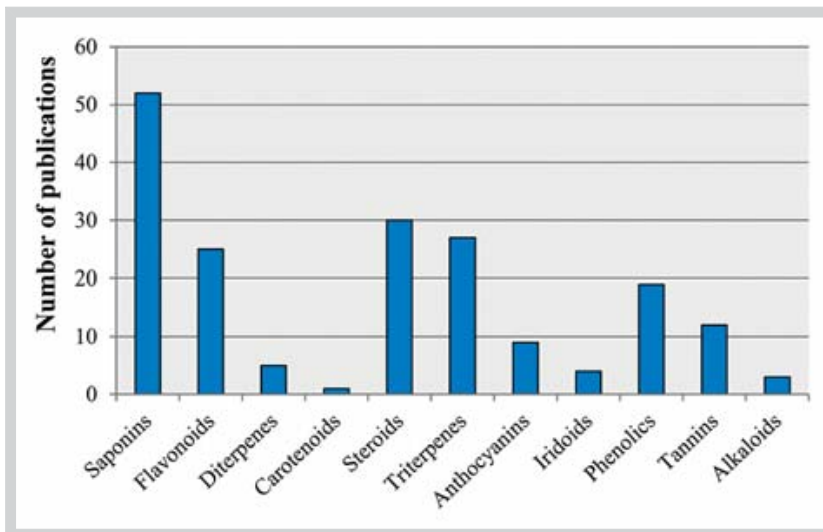

Fig. 4 Application of MALDI-MS for the study of glycosylated natural products from the period 1999-2010. (Color figure available online only.)

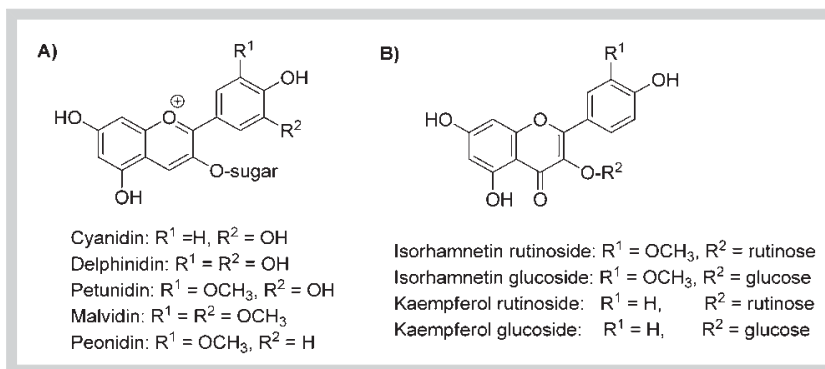

Fig. 5 Glycosylated anthocyanins (A) and flavonols (B) quantified by MALDI-TOF MS.

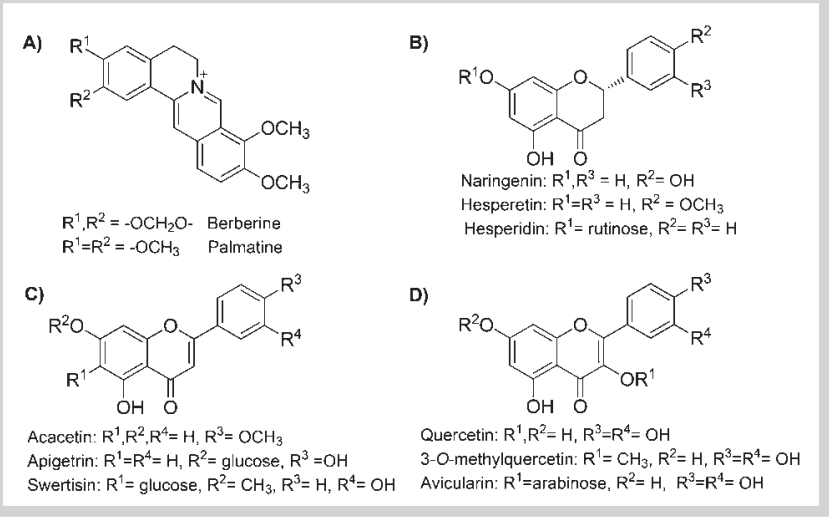

Fig. 6 Natural products analyzed by MALDI: quaternary protoberberine alkaloids (A) and some flavonoids (B flavanones, $\mathbf{C}$ flavones, and $\mathbf{D}$ flavanols).

for secondary metabolites analyses and their chemical reactions in the source, such as the evaluations performed with aromatic carboxylic acids and flavonoids $[22,81,82]$. The in-source dissociations of twenty-six flavonoids (glycosylated and non-glycosylated), including flavanones, flavones and flavonols (0 Fig. 6BD), were evaluated without a matrix and with different matrices. The in-source dissociations, the influence of laser intensity, and the applied matrix type were investigated. The flavonoid $O$-glycosides eliminated the sugar in-source, even in the presence of the 
Table 3 Data published between 2014 and 2015 for MALDI imaging from plant materials.

\begin{tabular}{|c|c|c|c|c|}
\hline Species & Sample & Class of compounds & Sample preparation & Ref. \\
\hline Accent Grape & Fruit & Anthocyanins & Cryosectioning $(10 \mu \mathrm{m})$; DAN matrix & [211] \\
\hline Allium cepa & Bulb & Flavonoids and others & Hand-cut sections; gold nanoparticle as the matrix & [212] \\
\hline Arabidopsis thaliana & Leaves & Glucosinolates & Intact surface; 9-AA matrix (sublimation) & [213] \\
\hline Arabidopsis thaliana & Seedlings & Phospholipids & Intact surface; CHCA and DHB, LDI (comparison) & [214] \\
\hline Arachis hypogaea (peanut) & Skin & Aflatoxins and stilbenoids & Imprinted in silica, matrix-free & [215] \\
\hline Capsicum annuum & Fruit & Alkaloids (capsaicinoids) & - & [216] \\
\hline Citrus sinensis & Leaves and petioles & Flavonoids & $\begin{array}{l}\text { Sectioning by microtome }(20 \mu \mathrm{m}) \text {; } \\
\text { CHCA:DHB }(1: 1) \text { matrix }\end{array}$ & [217] \\
\hline Eucalyptus globulus and E. grandis & Stem & Phenylpropenoids & Hand-cut sections; silica matrix & [218] \\
\hline Glycyrhiza glabra & Rizhome & Flavonoids and saponins & Cryosectioning $(20 \mu \mathrm{m})$; DHB matrix & [219] \\
\hline Gossypium hirsutum (cotton) & Seed & Polyphenols and others & Cryosectioning $(30-50 \mu \mathrm{m})$; DHB matrix & [220] \\
\hline $\begin{array}{l}\text { Gunnera manicata (symbiosis } \\
\text { with Blasia pusilla) }\end{array}$ & Stem & Nostopeptolides & Sectioning; universal MALDI matrix & [221] \\
\hline Hordeum vulgare & Grain & Sugars & Cryosectioning $(30 \mu \mathrm{m})$; DHB matrix & [222] \\
\hline $\begin{array}{l}\text { Hypericum perforatum, H. olym- } \\
\text { pucum and H. patulum }\end{array}$ & Leaves & Naphtodianthrone & Intact surface; $\mathrm{CHCA}$ matrix & [223] \\
\hline Linum usitatissimum & Flowers & Cyanogenic glucosides and lignans & Cryosectioning $(20 \mu \mathrm{m})$; DHB matrix & [118] \\
\hline Lupine & $\begin{array}{l}\text { Roots (interface } \\
\text { soil-root) }\end{array}$ & Pesticides & CHCA matrix & [224] \\
\hline Lychnophora species & Leaves & Flavonoids & Sectioning by microtome $(50 \mu \mathrm{m})$; matrix-free & [74] \\
\hline $\begin{array}{l}\text { Medicago truncatula (symbiosis } \\
\text { with Sinorhizobium meliloti) }\end{array}$ & Root nodules & Amino acids and others & Cryosectioning $(16 \mu \mathrm{m})$; DHB matrix & [225] \\
\hline Musa acuminata & Fruit (epidermis) & Phenylphenalenones & Microdissection; matrix-free & [226] \\
\hline Pisum sativum & Seed (pea) & $\begin{array}{l}\text { Phenylpropanoids, lignans and } \\
\text { pterocarpans }\end{array}$ & Pea (epidermal layer); DHB matrix & [227] \\
\hline Raphanus sativus & Bulbs and leaves & Anthocyanin and others & Cryosectioning $(12 \mu \mathrm{m})$; CHCA and DHB matrix & [228] \\
\hline Solanum habrochaites & Leaves & Flavonoids, sugars and glycoalkaloids & Intact surface; matrix-free (carbon) & [229] \\
\hline Soybean & Leaves & Flavonoids and others & Intact surface; matrix-free (2D graphene) & [230] \\
\hline Tomato, apple and nectarine & Cuticle & Fatty acids (chemical hydrolysis of cutin) & Cutin peaces; LiDHB matric & [231] \\
\hline Wheat & Leaves & Fungicides residues & Intact surface; DHB matrix & [210] \\
\hline Zea mays (maize) & Leaves & Flavonoids and phenylpropanoides & Cryosectioning $(10 \mu \mathrm{m})$; DAN matrix & [232] \\
\hline
\end{tabular}

matrix and in both ion modes, producing radical ions ([M - H-sug$\mathrm{ar}^{-*}$ ) in the negative ion mode, similar to ESI [83]. The MALDI conventional matrix application reduced the in-source fragmentation of $\mathrm{C}$ - and $\mathrm{O}$-glycosylated flavonoids, but they were not eliminated. In addition, the methyl radical losses from methoxylated flavonoids were completely eliminated only with the LiDHB matrix; besides this, all the retro Diels-Alder fragmentations in the source were also eliminated [22]. Thus, the use of a specific matrix may be required, depending on the drawn objectives and the type of molecular target.

Moreover, the screening and selection of bioactive compounds from extracts can be performed by MALDI-MS, including the search for specific enzymatic inhibitors and the establishment of the enzyme reaction kinetics constants $[84,85]$. A quantitative method by MALDI-FT MS was developed and used to analyze the product of the acetylcholinesterase enzymatic reaction and the potential inhibitors from Rhizoma Coptidis extracts. The assay interferents (acetylcholinesterase and cholinesterase) were eliminated by a high-resolution analyzer [85]. In addition, carbon nanotubes were used as a matrix to obtain the fingerprint spectra of Angelica sinensis (Oliv.) Diels Radix (Apiaceae) after metabolism with liver homogenate, and the quantitative differences of each metabolized compound were also studied [86]. The carbon nanotubes have been recently applied as a MALDI matrix for analyses of small compounds because of the absence of background matrix ions and efficiency in the ionization, but their low solubility in organic solvents and water, as well as ionization problems due to the presence of impurities (graphite pieces, metal particles, and amorphous carbon), in raw products and the con- tamination of the ion source represent the main disadvantages. However, the oxidation and chemical functionalization of carbon nanotubes has improved some of these problems, facilitating the sample preparation, since the water solubility is higher, and improving the efficiency of desorption/ionization analytes and reproducibility [87-89]. Finally, the adduction profiles of quinonethioether metabolites by cytochrome $\mathrm{C}$ have also been established by MALDI-TOF [90], as well as the identification of protein interactions, such as for hydrolysable and condensed tannins with bovine serum albumin [91,92]. Thus, the biological fingerprinting analyses by MALDI can be used for screening targets and assisting with studies of absorption, distribution, metabolism, elimination, and toxicity $[85,86,93]$.

\section{MALDI imaging}

MALDI imaging, another important technique in natural products chemistry, was introduced by Caprioli in 1997 and was initially applied to proteins and peptides [94]. The technique directly analyzes tissue using MS, producing maps of the ion tissue distribution. The highlighted advantage is not a necessity of the previous extraction of the compounds for analyses, avoiding the losses of information about spatial distribution [95]. This method was first used to analyze animal tissue, but currently includes other tissue analyses, such as plants, microorganisms, and insects [9,95-98]. There are some protocols of sample preparation from animal tissue for protein and peptide analyses; however, no universal methods of sample preparation and data processing for others tissues have been reported, such as for plants [9,94]. In addition, plant tissue analyses by MALDI imaging are far from being 
a routine technique, since there are many difficulties in preparing the samples and the requirements to adapt protocols for specific samples.

IMS has been successfully applied to diverse studies due to its high sensitivity (compounds of very low concentration can be analyzed; attomole to low femtomole range), selectivity (similar compounds can be differentiated), and ability to identify structurally the metabolites, since mass spectrometric data give chemical information useful to identify them $[9,69,73,75,99]$. The high mass accuracy obtained by high-resolution analyzers can be used to differentiate similar compounds that show differences only in their exact masses, as well as a reduction of the interference of matrix ions in the images. In addition, the images of tissue distributions of metabolites produced from MS/MS data have a higher selectivity, since the isomers (compounds with the same molecular formula) with unlike fragmentation pathways can be distinguished, producing images with high reliability $[9,73,100]$. Although IMS has been performed by other ionization methods, such as desorption electrospray ionization (DESI), laser ablation electrospray ionization (LAESI), and secondary ion mass spectrometry (SIMS), most studies applied MALDI and LDI techniques that are explainable because of their advantages, such as good spatial resolutions (around $20 \mu \mathrm{m}$ ) and a high speed of data acquisition (lasers with high frequency) $[9,75]$. The huge challenge of MALDI analysis is still the background matrix ions in the low mass range, the size crystals of the matrix, since it is directly related to spatial resolution, as well as the scarce information about the ionization and in-source dissociation of secondary metabolites to improve the data and result qualities.

The tissue distribution of specific metabolites can be established by MALDI imaging, unlike classical histochemical methods (unspecific) applied for plant tissue, making it possible to distinguish between individual compounds, which can be confirmed by MS/ MS data, and it has a high accuracy, which reduces the problems related to isobaric matrix ions and creates more reliable image data. However, most studies did not use MS/MS data and they only operate in full scan mode [9]. Some articles, including relevant reviews, have shown the application of MALDI imaging for plant tissues, food, and microorganisms (for example, to elucidate the interaction between them). They described diverse details about sample preparation, spectra acquisition, post-acquisition analysis, and data evaluation related to biosynthesis, spatial dynamic, ecology, physiology, and morphology [9,73,75,101-105]. So, new issues are reported here to extend the information not yet addressed in other review articles.

MALDI and LDI imaging have been used for analyses of fruits, leaves, stems, sepals, seeds, roots, tubers, flowers, pollen grains, and rhizomes $[9,73,75]$, such as from the leaves of Arabidopsis thaliana (L.) Heynh. (Brassicaceae - glucosinolates) [106], Lychnophora species (Asteraceae) [74], Hypericum perforatum L. and Hypericum reflexum L.f. (Hypericaceae) [107], apples [108], eggplant [109], and others. The details of MALDI imaging of plant tissue are not described here because excellent review articles have already been published in this area $[9,73,75,101,102,110,111]$. Recently, Bjarnholt and collaborators performed an extensive revision (up to 2013) about IMS from plant tissue, and almost 65\% applied MALDI and LDI for image acquisition using mainly CHCA and DHB as the matrix and cryosectioning to slice the materials [9]. The published articles, applying MALDI imaging from plants, between 2014 and 2015 are summarized in 0 Table 3 and some special review articles have been published from analytical strategies for data obtainment, including higher spatial resolution and sample preparation [112-116]. In addition, a recent published review summarized the advances of IMS for lipidomics, showing the insights related to the spatial compartmentalization of lipids and their metabolism in plants, and the matrices DHB and 9-AA are predominantly used for these analyses [117].

A critical step in MALDI imaging experiments is the sample preparation, which requires some special care to avoid the degradation or metabolization of the compounds. In addition, the vacuum in the source (not for atmospheric pressure MALDI) makes the analyses of transversal plant sections (in natura) difficult because of water losses in vacuum due to the tissue contraction, which makes the correlation between the MALDI imaging and anatomical data difficult, as well as the flatness of the tissue that may interfere in the accuracy. Another important point is about the spatial resolution of images, since the higher resolution (few microns) only has been presented by prototype machines produced in specialized research laboratories. The images at resolutions of $10-20 \mu \mathrm{m}$ are possible for commercial equipment, but the focus laser beam should be considered an experimental parameter and the size of the matrix crystals are also relevant [9, 73]. Nowadays, the use of MALDI imaging from plants is still limited, but it can give valuable information about surface metabolite and tissue distribution maps, which can assist in understanding the pathway biosynthetic, metabolite translocations, defense of plants, and others $[9,73,118]$. Although there are huge challenges for small compound analyses and plant tissues, MALDI imaging is a technique with many advantages and gives new perspectives in the natural products area, helping to explore and understand diverse issues, such as ecological and physiological.

\section{MALDI-MS/MS to identify natural products}

MALDI has been coupled to different analyzers such as quadrupole (Q), IT, orbitrap, TOF, and FT-ICR. The mass accuracy, resolution, $m / z$ range, sensitivity, speed, and other characteristics are different for each analyzer and should be selected to best fit the specific requirements of each experiment $[6,16,102,119,120]$. MS/MS is performed in two stages: the first includes ion precursor isolation and its activation, which subsequently leads to the fragment ions being separated and detected. The activation step involves increasing the internal energies of ions, resulting in the rupture of chemical bonds by homolytic and/or heterolytic fissions. Different ion activation methods are available such as low- and high-energy CID, electron capture dissociation (ECD), blackbody infrared dissociation (BIRD), surface-induced dissociation (SID), ultraviolet photodissociation (UVPD), electron transfer dissociation (ETD), electron-induced dissociation (EID), infrared multiphoton dissociation (IRMPD), and PSD [121]; however, not all of the methods are available for the MALDI system, and CID is most often applied.

Although MALDI-MS/MS is widely used to identify and characterize peptides, there is little information on its use for small compound natural products, especially on the in-source fragmentation and the gas reactions for ion activation methods with a high energy transfer. In addition, the influence of the amount of energy transferred in the ionization processes by MALDI and the subsequent fragmentation is poorly understood. Therefore, this review explored the use of MALDI-MS/MS for natural products identification and the principal considerations reported, which stimulates future studies to expand its applications.

The fragmentation of nine flavonoids (two aglycone flavones, one isoflavone, three aglycone flavonols, two $O$-glycosylated flavonols, and one flavanone) were compared by ESI-QTOF, MALDI- 
QIT, and MALDI TOF ReTOF; this latter method refers to the curved field reflectron or post-source decay, using the conventional MALDI matrices CHCA and DHB. The fragmentation using low energy, such as ESI-QTOF and MALDI-QIT, was similar, showing many similarities in the spectra related to the product ion and the relative ion signal intensity. MALDI TOF ReTOF applies high energy to ions, since the center-of-mass energy $\left(E_{\mathrm{cm}}\right)$ of the precursor ions produced by MALDI are reaccelerated to $20000 \mathrm{eV}$ $\left(E_{\mathrm{cm}} \approx 150-310 \mathrm{eV}\right)$. Thus, MALDI TOF ReTOF works at a higher energy than ESI-QTOF (accelerated to $30 \mathrm{eV}, E_{\mathrm{cm}}=1-4 \mathrm{eV}$ ) and MALDI-QIT $\left(E_{\mathrm{cm}} \leq 2 \mathrm{eV}\right)$ when compared to a specific ion [122]. The rare loss of a hydrogen radical from typical flavonoid fragments (for example, from ions produced by retro-Diels-Alder cleavages) was only observed in MALDI TOF ReTOF at high center-of-mass energies and included other radical ions, and no competing fragmentation processes at low center-of-mass energies have been observed $[121,122]$. The high center-of-mass energies have been described to induce charge-remote fragmentation and diverse fragmentation pathways, which may be useful in dereplication studies because they offer additional information for structural elucidation.

Through previous fragmentation studies of standards, compounds such as ferulic acid, wogonin (a flavone), and scutellarin (a glycoside flavone) could be identified in extracts of traditional Chinese medicine herbs by MALDI-MS/MS with graphene and graphene oxide matrices, which improved the limit of detection and reduced the in-source fragmentation. The graphene belongs to the multidimensional carbon nanomaterial family, which is composed of two dimensional layers of $\mathrm{sp}^{2}$ bonded carbon and recently it has been applied as a MALDI matrix for small compound analyses, since a low background interference of matrix ions is also observed in the spectra. In addition, the graphene oxide is easily produced by oxiding graphite, showing hydroxyl and epoxide groups on the base of the structural plane of graphene oxide sheets that confer strong hydrophilic properties and help water dispersion and swelling. The excellent results could be related to their properties such as thermal, electronic, and mechanical $[25,123]$. Specific matrices can reduce the in-source dissociation and significantly influence the final results. However, there is little information about ionization processes, in-source dissociations, and fragmentation by MALDI with high-energy CID, PSD, and LIFT. Fragmentation studies using high-energy CID, PSD, and LIFT are in demand because, as reported by March and coworkers [122], only fragmentation data obtained by low-energy CID are similar to ESI and MALDI for flavonoids, and such data are widely available for ESI.

Silva and Lopes [22] evaluated the in-source dissociations of various glycosylated and non-glycosylated flavonoids (flavanones, flavones, flavonols) without a matrix and with different matrices in addition to the influence of the laser intensity on these insource reactions. The flavonoid-matrix cluster ions, which depend on the structure of the flavonoid, were elucidated by MALDI-MS/ MS, confirming the formation of cluster ions involving fragments produced by retro-Diels-Alder fragmentation [124]. The formation of radical fragments in-source and MS/MS experiments are evident $[22,81,122,125]$, and increasing the understanding of these reactions will enlarge the application of MALDI as a tool in high-throughput chemical analysis and the identification of natural products $[25,27,51,55,68,126]$.

Although the 0 -glycosylated flavonoids easily lose the sugar in the source, Wang and Sporns [68] thoroughly studied the fragmentation pathway of glycosylated flavonols with up to three glycosides. The best matrix reported by the authors was THAP, because it had good repeatability (spot-to-spot), produced ions in both positive and negative ion modes, and exhibited a high affinity for alkali metals in the ionization process. The main fragment ions were generated from sugar losses, as observed in ESI [127]. However, the fragment ions produced from the aglycone were not described [68], which is important for its elucidation. PSD for TOF analyzers and the LIFT system have been employed in MS/MS experiments, and both can be associated with CID to increase the internal energy of the ions, thus increasing fragment ions $[128,129]$. Metastable fragments are produced from ions with excess internal energy during ion acceleration from the source in the free field region, and the reflector voltage is set to detect these fragments in the PSD technique. However, PSD is time consuming, and difficulties exist in mass calibration and the detection of fragments with a low $m / z(<150)$ [129]. In LIFT experiments, a low voltage of $8 \mathrm{kV}$ is applied to a precursor ion for acceleration; the ion is then isolated and raised to a higher potential in the LIFT cell. Subsequently, the fragment ions are reaccelerated toward the detector, and changes in the reflector voltage are not required [129]. PSD and LIFT were used to analyze clusters of the CHCA matrix, demonstrating the many advantages of the LIFT technique, with a better detection of ions with a low abundance and mass, and a relatively fast acquisition time [130]. Initially, PSD was applied in peptides $[131,132]$ and carbohydrate sequencing [133], and currently, there are some applications in natural products studies. It was used to identify saponins [134], flavonoids [122], isoflavones [135], carotenoids [136], and hydrolysable and condensed tannins $[66,137]$ as well as to examine triacylglycerols and phosphatidylethanolamines from plants, algae, and animal tissue [138-140].

Different carotenes (polyenes without oxygen) and xanthophylls (polyenes with oxygen) were analyzed by MALDI and produced radical ions (molecular ions) through the removal $\left(\mathrm{M}^{\circ+}\right)$ of one electron ( Fig. 7) [136], which is similar to ESI and FAB. The increase of a conjugation extension is a relevant factor for electron loss and radical stability, and produces spectra complexes from sequential in-source homolytic cleavages, as observed in the MALDI source $[4,23,141-143]$. The fragmentation patterns of carotenoids and xanthophylls were proposed based on MALDIPDS data $[23,136]$. The loss of one molecule of water [M-18 $]^{++}$ confirms the presence of a hydroxyl group (such as for luteolin), and $[\mathrm{M}-92]^{++}$and $[\mathrm{M}-106]^{-+}$ions are diagnostic of toluene and xylene losses, respectively. The intensity relation between these

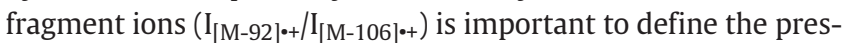
ence of double bonds, and when this relation is $>10$, the carotenoids contain nine double bonds. The loss of fatty acids ([M$\mathrm{RCOOH}]^{\circ+}$ ) is common for carotenoid fatty acid esters (such as for $\beta$-cryptoxanthin palmitate) and characterizes their presence in the carotenoid structures, while the epoxy species can be confirmed by the fragment ion $[\mathrm{M}-80]^{\circ+}$. Other diagnostic carotenoid fragment ions have been described in detail and are useful for elucidating their chemical structures $[23,136]$.

The 0 -glycosylated isoflavones from soy [Glycine max L. (Fabaceae)] showed fragments with structural importance by PSD, including the main fragment that occurs through the loss of sugars, which is similar to ESI. In addition, the DHB and THAP matrices were evaluated, and DHB showed better ionization results and a higher number of fragments in MS/MS spectra [135]. PSD was also applied in the study of peracetylated isoflavone glycosides from their protonated and cationized different metal ions to understand the gas phase molecule cluster complexes. A reduc- 
tion in the number of fragments was detected in the order of $\mathrm{Li}^{+}>$ $\mathrm{Na}^{+}>\mathrm{Ag}^{+}>\mathrm{Cu}^{+}>\mathrm{H}^{+}>\mathrm{K}^{+}>\mathrm{Rb}^{+} \approx \mathrm{Cs}^{+}$[144]. Fragmentation was lower for $\mathrm{Ag}_{3}{ }^{+}$clusters than $\mathrm{Ag}^{+}$, demonstrating a stronger gas phase interaction with $\mathrm{Ag}_{3}{ }^{+}$[145].

Saponins have been studied using different fragmentation techniques and, in some cases, the fragmentation was applied in dereplication studies. MALDI has limited applications in this area and is sometimes used together with LC-ESI-MS/MS data because more saponins can be identified and detected by MALDI [51,146, 147]. ESI-IT, MALDI-IT, MALDI-IT/TOF, and MALDI-TOF/TOF, including high-energy CID, were applied for dammarane-type triterpenoid saponins from Bacopa monnieri (L.) Wettst. (Plantaginaceae) [134]. In low energy techniques, the spectra were similar for ESI and MALDI ionization, and their product ions are applied to elucidate the sequence and branching of the sugar moieties $[134,147]$. The useful fragment ions from the aglycones and the glycosidic moiety were obtained from high-energy CID, which yielded the same fragments observed by PSD [134] and showed a similar charge-remote fragmentation described for high-energy CID for conjugated steroids and others $[148,149]$. These diagnostic fragment ions were also observed by the LIFT system, which assisted in the structural identification of saponins from the sea cucumber Holothuria forskali [150,151].

Hydrolysable and condensed tannins are another group of secondary metabolites analyzed by MALDI due to its advantages, such as sensitivity, the formation of singly charged molecular ions, and lower ion suppression for complex mixture analysis $[66,128,137,152]$. Several articles have reported the potential to identify such compounds by MALDI-MS, which contains different combinations and connectivity between the monomers and produces tannins of the same molecular weight. However, unambiguous identification can only be completed with MS/MS data, establishing the linkage between the specific monomers. Monomer losses involving fragment ions by hydrogen transfer and typical retro-Diels-Alder fragmentations are observed from each oligomer, followed by water elimination, but the radical fragment ions are less visible in the spectra [153-157]. These observations were applied to identify condensed tannins of A-type and B-type linkages from different species described from Theobroma cacao L. (Sterculiaceae) [153], Salix alba L. (Salicaceae), Picea abies (L.) H. Karst (Pinaceae), Fagus sylvatica L) (Fagaceae), Tilia cordata Mill. (Malvaceae) [66], Cinnamomum zeylanicum L. (Lauraceae) [154], Eugenia dysenterica DC. (Myrtaceae) [155], quebracho wood [128], Commiphora leptophloeos (Mart.) J. B. Gillett (Burseraceae), Anadenanthera colubrina (Vell.) Brenan var. colubrina (Fabaceae), Myracrodruon urundeuva Allemão (Anacardiaceae) [156], Pityrocarpa moniliformis (Benth.) Luckow \& R.W. Jobson (Fabaceae) [157], almond [158], and others. In addition, it allowed for the identification of a rare polymeric series of up to eight flavan-3-ol units with pentose and hexose sugars by MALDI-TOF/ TOF LIFT [153].

MS/MS data obtained by MALDI QIT-TOF, PSD, and CID have been applied to determine the chemical structure of hydrolysable tannins from Rosa chinensis Jacq. (Rosaceae) [159], Chinese galls [59], tara, Turkey gall, chestnut woods [137], Mangifera indica L. (Anacardiaceae) [160], and others, which are preferentially acquired in the positive ion mode due to the visualization of fewer signal peaks in the negative ion mode for gallotannins [59]. However, an extensive application of different matrices must be evaluated to confirm this statement. The hydrolysable tannins were also evaluated by MALDI-TOF/TOF (positive ion mode) with two cationizing agents, sodium and cesium, but significant differences in the fragmentation pathway were not observed [160,161]. First, the galloyltannins lost one or more galloyl moieties (152 Da), accompanied by the loss of one or more molecules of $\mathrm{H}_{2} \mathrm{O}$. The molecules of gallic acid ( $170 \mathrm{Da}$ ) or ellagic acid, when present, can be lost with the hydrogen transfer, and a double bond in the glucose is formed [137]. Many important fragment ions were not observed by ESI-MS/MS, which could complicate their structural identification [162-165]. A complex fragmentation pattern obtained from $<300 \mathrm{Da}$ is observed, which complements the information to identify them $[59,137,160]$. The fragment ions from sugar core tannins can be observed, occurring by the internal cleavage of the glycosidic ring, with a similar fragmentation already reported for carbohydrates by MALDI-CID [166,167].

MALDI-MS is an advantageous technique for macromolecule analyses due to the characteristics described previously, and currently, its application to small molecules is just beginning [24,26, 28]. Although more research in this area is required, MALDI-MS has demonstrated valorous contributions to secondary metabolites over other analytical techniques [50]. Many publications described the use of MALDI-MS for establishing metabolic fingerprints $[6,27,168,169]$. A chemical profile of the compounds and the use of MALDI-MS/MS to identify the chemical structure of natural products are recent and not extensively applied in the identification of tannins (hydrolysable and condensed) and saponins. In addition, few studies by MALDI-MS/MS have been described for a restricted number of natural compounds, such as anthocyanins, carotenoids, xanthophylls, betaines, glycosylated isoflavones, phenolic acids, flavonoids, theaflavins and thearubigins, limonoids, alkaloids, and others, which are sometimes combined with LC-ESI-MS/MS data $[23,25,68,74,122,125,126,136$, $143,153,159,168-171]$.

All the statements appointed here confirm the relevant MALDI applications in the natural products area, stimulating its applications in wide studies such as the research of biomarkers, hierarchical clustering, taxonomy, imaging from tissues, and others. However, the data processing is fundamental to improve the quality of results and to avoid mistaken conclusions. So, the data analysis can be divided into the steps of preprocessing and statistical analysis. The preprocessing will be described here, since it is extremely important and restrictedly described in the literature.

\section{Data Processing \\ $\nabla$}

In the previous section, we have shown a broad range of MALDI ionization applications to natural products. Due to the mass spectrometer hardware and the advances in applications, many authors consider that data analysis is going to play an important role in most of these applications and will become a bottleneck for many inquiry fields $[172,173]$.

In many cases, specific techniques are required to analyze a sample and to answer a scientific question, for example, by MALDI imaging or a MALDI-MS/MS data set. Each spectrum in an experimental data set, usually composed of many samples and replicates, should be processed to improve the results and thus guide the study to correct conclusions [174]. For this reason, a common modular analysis flow diagram was proposed here, and some applications to MALDI-MS data were described to exemplify the addressed points. Following this flux analysis, here the similarities with MS data obtained by other ionization methods and more generically for other large-scale data sampling techniques are highlighted. The optimization of data analysis steps described be- 
low is much more critical to correctly associate patterns in data to the studied biological changes.

In the following, each step presented in $\odot$ Fig. 8 will be briefly explored, highlighting its importance to an unbiased analysis, reviewing applications for MALDI-MS data and software availability. Some steps, such as smoothing and baseline removal, may switch their locations in the analysis flux [175]. In O Fig. 8, the position of visualization is presented as a parallel procedure to all analysis steps, highlighting the importance to plot spectra summaries before and after preprocessing. Morris and collaborators [175] showed how simple heat maps allowed the discovery of unexpected data patterns.

The intensity of a given $m / z$ value is proportional to the relative abundance of an ion represented by this $m / z$ value [174]. Given a set of $S$ spectra containing information from a total of $n$ small molecules, the goal of our analysis flux is to generate an $S \times \mathrm{m} \mathrm{ma-}$ trix, whose rows correspond to the individual spectrum, and the columns contain some (relative) quantification of a molecule (or mass signal associated with a molecule) [175]. This matrix, which represents a multidimensional data set, is generated through the preprocessing described in $\odot$ Fig. 7 , and the final goal is to associate changes or patterns in this data set with our studied problem. According to Ge and Wong [176], a mass spectrum can theoretically be decomposed into three components: the baseline value, the true signal, and the noise. Therefore, baseline and noise can be potentially associated with inter- and intra-sample variability, and data preprocessing is required to reduce the baseline and noise in the raw data before any multivariate analysis can occur $[177,178]$.

Morris and collaborators [175] showed illustrative examples that ignore the basic assumption of experimental planning, namely, blocking and randomization, and how it can completely compromise an experiment. The authors also showed how a change in the biological sample collection protocol after the first 20 subjects had been collected resulted in changes between the subtypes of cancer studied that could not be attributed to the biological question, instead it could be easily attributed to systematic and reproducible changes due to the experimental procedure. Oberg and Vitek [179] discuss how randomization, replication, and blocking helped to avoid systematic biases due to the experimental procedure and assisted in optimizing its ability to detect true quantitative changes between groups in mass spectrometrybased proteomic experiments. The importance of experimental design in mass spectrometry has been reviewed $[180,181]$. The experimental design is also commonly used to test the combination of two or more factors of interest. Zhang et al. [182] obtained optimum automated data acquisition settings that yielded the highest reproducibility of replicate mass spectra based on experimental design statistical analysis of intact cell MALDI-MS spectra of Pseudomonas aeruginosa.

According to Xiang and Prado [183], the calibration methods are usually divided into two classes for high-resolution analyzers (mostly TOF analyzers): external and internal. The authors recorded a standard sample in a separate spectrum, in the external calibration process, and the calibration parameters were drawn from this standard sample and used to calibrate samples in other spectra. In the internal calibration process, standard molecules were mixed with the sample, a spectrum of the mixture acquired, and standard molecules peaks were identified and used to calibrate the entire spectrum. Fraser and coworkers [64] have used a single point external calibration and achieved mass accuracies of $10-70 \mathrm{ppm}$ in MALDI-TOF analyses. When the same authors

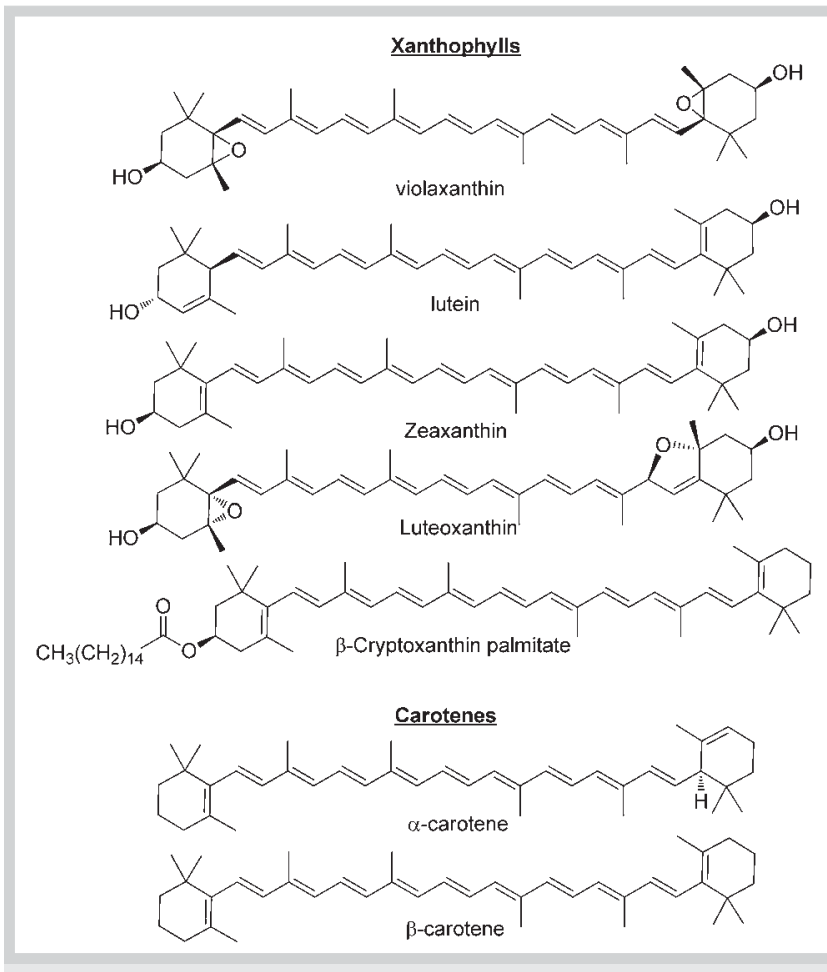

Fig. 7 Chemical structures of some xanthophylls and carotenes analyzed by MALDI-PSD MS/MS.

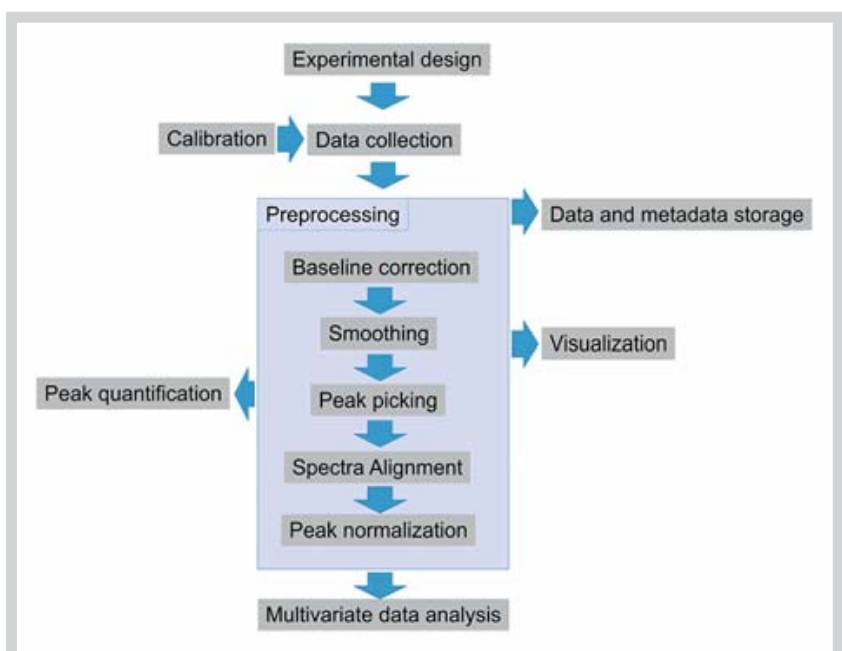

Fig. 8 A flow diagram of the modular analysis of MALDI-MS data. Different modular elements in different ordinations can be used for a specific purpose. (Color figure available online only.)

used an internal calibration, using two carotenoid calibrants flanking the $m / z$ of interest, they achieved mass accuracies below $10 \mathrm{ppm}$. Saideman and coworkers [184], using internal calibration, have determined peptide mass accuracies ranging from 0.124 to $5.17 \mathrm{ppm}(\mathrm{n}=3)$.

The baseline is associated with a series of matrix materials, impurities, ionization by-products, electronic signal noise, and sample preparation contamination $[177,185,186]$. Baseline correction methods were reviewed by Hilario and collaborators [187]. 
The MALDIquant package [188] implements different approaches to adjust the baseline. The package's default is the Statistics-sensitive Non-linear Iterative Peak-clipping (SNIP) algorithm proposed by Ryan and collaborators [189] that yields a smooth baseline and leads to positive corrected intensities.

Systematic shifts can appear in repeated experiments, and the spectra for two identical metabolites can have different $m / z$ values. The spectral alignment consists of aligning corresponding peaks across samples to address this problem [190]. For a given $\mathrm{m} / \mathrm{z}$ value selected in different spectra, the peak position can differ slightly, and generally, this effect cannot be corrected by the instrument calibration [174].

The spectral alignment is a theme of constant research. A simple approach for spectral alignment is presented by Pham and Jimenez [172], in which peaks in individual spectra are matched against the closest peak in a mean spectrum. He and coworkers [191] compared several algorithms currently in use for mass spectrometry and showed that their correlations-based algorithm performed better in a SELDI-MS dataset. The alignment method described by He and coworkers [191] is also implemented in the MALDIquant package. Bloemberg and coworkers [192] wrote a comprehensive tutorial explaining the working principles of several methods and provided implementations in R [193] and Matlab (The Mathworks Inc.) languages.

Many spectral smoothing methods generate an intensity value by averaging the values within a span of data points. Smoothing is directly proportional to the span size (i.e., the segment size containing a specific number of $m / z$ ratio data points); therefore, care must be taken when choosing the span size, as a large span size may lead to information loss. Smoothing is important to correctly estimate the noise and to improve the peak picking process [187]. Several algorithmic procedures for informative peak identification have been proposed, named as peak detection or peak picking, that correspond to true signals. A comparative review of some of these algorithms, their principles, implementations, and performance is presented by Yang and collaborators [194]. The author concluded that continuous wavelet transform (CWT)based algorithms provided the best performance. The peak picking process is important in extracting the relevant signals from a mass spectrum and for its significant reduction of the data set dimensionality. Different implementations are available in the $\mathrm{R}$ package MALDIquant, as well as on XCMS [195], which can be straightforwardly adapted for MALDI-MS data.

In repeated experiments, it is common to observe differences arising from sample preparation and instrumental measure variation, which cannot be attributed to differences in the biological samples. Normalization is the transformation of sample-wise mass intensities to the same scale, which enables the comparison of different samples [196]. The impact of normalization was addressed by Ejigu and collaborators [197] in an LC-MS study. The authors state that normalization should be regarded more as a remedial measure, not to correct for all sources of variability introduced by different sources of biases. The authors also recommend data-driven (assuming that a large amount of the metabolites stay constant) normalization methods over model-driven (based on internal standards or intermediate quality control runs) normalization methods. Deininger and coworkers [198] have shown the importance of normalization in MALDI imaging experiments, where the incorrect normalization could completely change the potential biomarker spatial distribution. According to the same authors, median and noise level normalizations were significantly more robust than TIC normalization.
The success of multivariate data analysis depends heavily on the correct execution of the previous analysis steps. For example, incorrect peak picking can leave out peaks from important molecules, incorrect alignment can merge peaks from different molecules, and incorrect normalization can show intensity differences caused by the experimental procedure in place of biological differences. These mistakes impact the conclusions drawn from multivariate methods.

The multivariate analyses are commonly classified into two groups: unsupervised and supervised methods. Unsupervised methods are used on exploratory data analysis and make use of the data latent structure, without any previous assumption of sample classes. Supervised methods use information from the data structure and sample classes to estimate the model parameters [199].

From a large dataset, it is possible to predict the desired outcome only by chance. There are good confidence measures available to check the consistency of this analysis. For the most common unsupervised analysis, the hierarchical clustering, resampling, and regrouping techniques provide a consistence check [200]. For classification models (supervised analysis), care must be taken. A very popular model in the natural products community is PLS (partial least squares), which is prone to overfitting [201]. To avoid overfitting, an important technique in the classification models is the K-fold cross validation (CV) [175]. Many hybrid exploration/classification approaches have been proposed on MALDI. Alexandrove and coworkers [202] developed a spatially aware clustering approach for MALDI imaging. Briefly, the spectra are grouped by a measure of similarity taking into account its position, and then all pixels are pseudo-color coded according to the classification assignment. Pham and Jimenez [172] employed a grid search with exponential spacing to find the optimal values for support vector machine model selection. The authors report a final accuracy of $83 \%$ on a separate validation set (Breast Cancer Study with MALDI-MS Data) of 78 samples.

Tong and coworkers [177] argue that there is a lack of guidelines for data processing, and unexperienced practitioners can add variation when handling complex models. The authors also state that the functionalities of many tools designed for SELDI-MS or LC-ESI-MS are not transferable to MALDI-MS data analysis. As there is constant development of new computational statistical methods, many scientific communities are fostering the development of modular software in such a way that the modules can be combined to achieve different goals [203]. There is also an increasing realization of data standards, data storage, and exchange $[204,205]$. These good experimental practices will ultimately allow improvement in experimental reproducibility among different research groups and promote faster improvements in the groups that successfully adopt these practices.

He and coworkers [185] have a similar opinion regarding the difficulties of experimentalists in using software toolkits. The authors recommend the use of flexible software platforms that enable new users to construct new fit-to-purpose workflows. The authors cite case-based reasoning (CBR), a process of solving new problems based on the solutions of similar past problems [206].

There is also an agreement that most of the complex experiments should be performed by multidisciplinary groups and that data analysis in particular could benefit from the participation of statisticians, computer scientists, or more generally quantitative scientists. Their participation would be effective if they could be 
present in all phases from study design to interpretation of information extracted from experimental data $[175,177,185]$.

\section{Conclusions}

MALDI-MS is an underexplored technique in natural products chemistry, but the advantages encourage its use in the field. Its advantages include decreased ion suppression in complex mixtures, increased speed, higher tolerance to impurities, increased sensitivity, and low sample consumption compared to ESI. MALDI techniques can be applied to various fields of study, including studies of structural identification, tissue imaging, metabolomics, molecular interactions with target molecules, medicinal plant identification, quantification, and chemical screening. Although several points are unknown in secondary metabolite analysis, MALDI has been successfully applied, thus demonstrating its potential and usefulness for the analyzed metabolite classes listed in this review. Several types of metabolites can be analyzed by MALDI, such as hydrolysable and condensed tannins, alkaloids, saponins, flavonoids, anthocyanins, sesquiterpene lactones, carotenoids, steroids, diterpenes, and lipids, including glycosylated and non-glycosylated compounds. The development of chemical analysis guidelines for different metabolite classes, as in this review and others in the future, will assist in the planning of the experimental design, interpretation, and data processing. In addition, the MALDI-MS/MS data obtained by low energy transfer methods can be easily compared to ESI fragmentation, facilitating its use in the structural identification of compounds because several ESI-MS/MS fragmentation pathways have already been reported. Additionally, fragment ions are often different due to charge-remote fragmentation in the high energy transfer methods of MS/MS that are commonly applied in MALDI analyses. These fragment ions can give additional and useful information for structural identification, as observed, for example, in carotenoids, saponins, and tannins. However, more studies on the fragmentation mechanisms for different metabolite classes are required.

With the increasing availability of MALDI experimental applications, dedicated software is needed; however, for most analytical needs, numerous powerful algorithms and free software implementations are available. The scientist's main task is to understand the data structure and assumptions of an analytical method and correctly apply it to their own data sets. Most readers may not have experience with data analysis, and the availability of dedicated software is important, but this review sought to recognize data analysis as an important point in the experimental process and emphasize the importance of data analysts in multidisciplinary groups.

\section{Acknowledgments}

$\nabla$

The authors thank FAPESP (Process: 2009/54098-6, 2012/180317, 2014/20302-4 and 2014/01884-2), CNPq, INCT_if, CAPES, and FUNDECT.

\section{Conflict of Interest}

\section{$\nabla$}

The authors declare that no conflicts of interest exist.

\section{References}

1 Gohlke RS, McLafferty FW. Early gas chromatography/mass spectrometry. J Am Soc Mass Spectrom 1993; 4: 367-371

2 Karas M, Bachmann D, Bahr U, Hillenkamp F. Matrix-assisted ultraviolet laser desorption of non-volatile compounds. Int J Mass Spectrom Ion Process 1987; 78: 53-68

3 Karas $M$, Krüger $R$. Ion formation in MALDI: the cluster ionization mechanism. Chem Rev 2003; 103: 427-439

4 Guaratini T, Vessecchi RL, Lavarda FC, Maia Campos PM, Naal Z, Gates PJ, Lopes NP. New chemical evidence for the ability to generate radical molecular ions of polyenes from ESI and HR-MALDI mass spectrometry. Analyst 2004; 129: 1223-1226

5 Crotti AEM, Vessecchi R, Lopes JLC, Lopes NP. Espectrometria de massas com ionização por "electrospray": processos químicos envolvidos na formação de íons de substâncias orgânicas de baixo peso molecular. Quim Nova 2006; 29: 287-292

6 Ernst M, Silva DB, Silva RR, Vêncio RZN, Lopes NP. Mass spectrometry in plant metabolomics strategies: from analytical platforms to data acquisition and processing. Nat Prod Rep 2014; 31: 784-806

7 Dorrestein PC. Editorial: Mass spectrometry of small molecules and natural products. Nat Prod Rep 2014; 31: 704-705

8 Bhardwaj C, Hanley L. Ion sources for mass spectrometric identification and imaging of molecular species. Nat Prod Rep 2014; 31: 756-767

9 Bjarnholt $N$, Li B, D'Alvise J, Janfelt C. Mass spectrometry imaging of plant metabolites - principles and possibilities. Nat Prod Rep 2014; 31: 818-837

10 Shih CJ, Chen PY, Liaw CC, Lai YM, Yang YL. Bringing microbial interactions to light using imaging mass spectrometry. Nat Prod Rep 2014; 31: 739-755

11 Zenobi R, Knochenmuss $R$. Ion formation in MALDI mass spectrometry. Mass Spectrom Rev 1998; 17: 337-366

12 Knochenmuss $R$, Zenobi R. MALDI ionization: the role of in-plume processes. Chem Rev 2003; 103: 441-452

13 Dreisewerd $K$. The desorption process in MALDI. Chem Rev 2003; 103: 395-426

14 Holle A, Haase A, Kayser M, Hohndorf J. Optimizing UV laser focus profiles for improved MALDI performance. J Mass Spectrom 2006; 41: 705-716

15 O'Connor PB. The development of matrix-assisted laser desorption/ionization sources. In: Cole RB, editor. Electrospray and MALDI mass spectrometry: fundamentals, instrumentation, practicalities, and biological applications. Hoboken: John Wiley \& Sons; 2010: 185-213

16 Bier ME. Coupling ESI and MALDI sources to the quadrupole mass filter, quarupole ion trap, linear quadrupole ion trap, and orbitrap analyzers. In: Cole RB, editor. Electrospray and MALDI mass spectrometry: fundamentals, instrumentation, practicalities, and biological applications. Hoboken: John Wiley \& Sons; 2010: 265-344

17 El-Aneed A, Cohen A, Banoub J. Mass spectrometry, review of the basics: electrospray, MALDI, and commonly used mass analyzers. Appl Spectrosc Rev 2009; 44: 210-230

18 Creaser CS, Griffiths JR, Bramwell CJ, Noreen S, Hill CA, Thomas CLP. Ion mobility spectrometry: a review. Part 1 . Structural analysis by mobility measurement. Analyst 2004; 129: 984-994

19 Kanu AB, Dwivedi P, Tam M, Matz L, Hill jr. HH. Ion mobility-mass spectrometry. J Mass Spectrom 2008; 43: 1-22

20 Hossain M, Limbach PA. A comparison of MALDI matrices. In: Cole RB, editor. Electrospray and MALDI mass spectrometry: fundamentals, instrumentation, practicalities, and biological applications. Hoboken: John Wiley \& Sons; 2010: 215-261

21 Gabelica V, Schulz E, Karas M. Internal energy build-up in matrix-assisted desorption/ionization. J Mass Spectrom 2004; 39: 579-593

22 Silva DB, Lopes NP. MALDI-MS of flavonoids: a systematic investigation of ionization and in-source dissociation mechanisms. J Mass Spectrom 2015; 50: 182-190

23 Kaufmann R, Wingerath T, Kirsch D, Stahl W, Sies H. Analysis of carotenoids and carotenol fatty acid esters by matrix-assisted laser desorption ionization (MALDI) and MALDI post-source-decay mass spectrometry. Anal Biochem 1996; 238: 117-128

24 Dong X, Cheng J, Li J, Wang Y. Graphene as a novel matrix for the analysis of small molecules by MALDI-TOF MS. Anal Chem 2010; 82: 62086214

25 Liu Y, Liu J, Yin P, Gao M, Deng C, Zhang X. High throughput identification of components from traditional Chinese medicine herbs by utilizing graphene or graphene oxide as MALDI-TOF-MS matrix. J Mass Spectrom 2011; 46: 804-815 
26 Cohen LH, Gusev AI. Small molecule analysis by MALDI mass spectrometry. Anal Bioanal Chem 2002; 373: 571-586

27 Ernst M, Silva DB, Silva R, Monge M, Semir J, Vêncio RZN, Lopes NP. A metabolomic protocol for plant systematics by matrix-assisted laser-desorption/ionization time-of flight mass spectrometry. Anal Chim Acta 2015; 859: 46-58

28 McCombie G, Knochenmuss R. Small-molecule MALDI using the matrix suppression effect to reduce or eliminate matrix background interferences. Anal Chem 2004; 76: 4990-4997

29 Liu R, Liu JF, Yin YG, Hu XL, Jiang GB. Ionic liquids in sample preparation. Anal Bioanal Chem 2009; 393: 871-883

30 Vorm $O$, Roepstorff $P$, Mann M. Improved resolution and very high sensitivity in MALDI TOF of matrix surfaces made by fast evaporation. Anal Chem 1994; 66: 3281-3287

31 Gobey J, Cole M, Janiszewski J, Covey T, Chau T, Kovarik P, Corr J. Characterization and performance of MALDI on a triple quadrupole mass spectrometer for analysis and quantification of small molecules. Anal Chem 2005; 77: 5643-5654

32 Dai Y, Whittal RM, Li L. Two-layer sample preparation: a method for MALDI-MS analysis of complex peptide and protein mixtures. Anal Chem 1999; 71: 1087-1091

33 Cheng ZH, Guo YL, Wang HY, Chen GQ. Qualitative and quantitative analysis of quaternary ammonium alkaloids from Rhizoma Corydalis by matrix-assisted laser desorption/ionization Fourier transform mass spectrometry coupled with a selective precipitation reaction using Reinecke salt. Anal Chim Acta 2006; 555: 269-277

34 Abell DC, Sporns P. Rapid quantitation of potato glycoalkaloids by matrix-assisted laser desorption/ionization time-of-fight mass spectrometry. J Agric Food Chem 1996; 44: 2292-2296

35 Shrivas K, Patel DK. Quantitative determination of nicotinic acid in micro liter volume of urine sample by drop-to-drop solvent microextraction coupled to matrix assisted laser desorption/ionization mass spectrometry. Spectrochim Acta A Mol Biomol Spectrosc 2011; 78: 253-257

36 Wang J, Kalt W, Sporns P. Comparison between HPLC and MALDI-TOF MS analysis of anthocyanins in highbush Blueberries. J Agric Food Chem 2000; 48: 3330-3335

37 Wang J, Sporns $P$. Analysis of anthocyanins in red wine and fruit juice using MALDI-MS. J Agric Food Chem 1999; 47: 2009-2015

38 Marczak L, Kachlicki P, Kozniewski P, Skirycz A, Krajewski P, Stobiecki M. Matrix-assisted laser desorption/ionization time-of-flight mass spectrometry monitoring of anthocyanins in extracts from Arabidopsis thaliana leaves. Rapid Commun Mass Spectrom 2008; 22: 3949-3956

39 Frison-Norrie S, Sporns P. Identification and quantification of flavonol glycosides in almond seedcoats using MALDI-TOF MS. J Agric Food Chem 2002; 50: 2782-2787

40 Champy P, Melot A, Guérineau Eng V, Gleye C, Fall D, Höglinger GU, Ruberg M, Lannuzel A, Laprévote O, Laurens A, Hocquemiller R. Quantification of acetogenins in Annona muricata linked to atypical Parkinsonism in Guadeloupe. Mov Disord 2005; 20: 1629-1633

41 Sleno L, Volmer DA. Toxin screening in phytoplankton: detection and quantitation using MALDI triple quadrupole mass spectrometry. Anal Chem 2005; 77: 1509-1517

42 May LA, Tourkina E, Hoffman SR, Dix TA. Detection and quantitation of curcumin in mouse lung cell cultures by matrix-assisted laser desorption ionization time of flight mass spectrometry. Anal Biochem 2005; 337: 62-69

43 Ivanova B, Spiteller $M$. Simultaneous quantitation of naturally occurring insecticides, acaricides, and piscicides in rapeseed oil by UV-MALDI mass spectrometry. J Food Meas Charact 2014; 8: 15-28

44 Harvey DJ. Analysis of carbohydrates and glycoconjugates by matrixassisted laser desorption/ionization mass spectrometry: an update covering the period 1999-2000. Mass Spectrom Rev 2006; 25: 595662

45 Harvey DJ. Analysis of carbohydrates and glycoconjugates by matrixassisted laser desorption/ionization mass spectrometry: an update covering the period 2001-2002. Mass Spectrom Rev 2008; 27: 125201

46 Harvey DJ. Analysis of carbohydrates and glycoconjugates by matrixassisted laser desorption/ionization mass spectrometry: an update for 2003-2004. Mass Spectrom Rev 2009; 28: 273-361

47 Harvey DJ. Analysis of carbohydrates and glycoconjugates by matrixassisted laser desorption/ionization mass spectrometry: an update for the period 2005-2006. Mass Spectrom Rev 2011; 30: 1-100
48 Harvey DJ. Analysis of carbohydrates and glycoconjugates by matrixassisted laser desorption/ionization mass spectrometry: an update for 2007-2008. Mass Spectrom Rev 2012; 31: 183-311

49 Harvey DJ. Analysis of carbohydrates and glycoconjugates by matrixassisted laser desorption/ionization mass spectrometry: an update for 2009-2010. Mass Spectrom Rev 2015; 34: 268-422

50 Chen X, Kong L, Su X, Pan C, Ye M, Zou H. Integration of ion-exchange chromatography fractionation with reversed-phase liquid chromatography-atmospheric pressure chemical ionization mass spectrometer and matrix-assisted laser desorption/ionization time-of-flight mass spectrometry for isolation and identification of compounds in Psoralea corylifolia. J Chromatogr A 2005; 1089: 87-100

51 Chapagain BP, Wiesman Z. Metabolite profiling of saponins in Balanites aegyptiaca plant tissues using LC (RI)-ESI/MS and MALDI-TOF/MS Metabolomics 2008; 4: 357-366

52 Duncan MW, Roder H, Hunsucker SW. Quantitative matrix-assisted laser desorption/ionization mass spectrometry. Brief Funct Genomic Proteomic 2008; 7: 355-370

53 van Kampen JJA, Burgers PC, de Groot R, Luider TM. Qualitative and quantitative analysis of pharmaceutical compounds by MALDI-TOF mass spectrometry. Anal Chem 2006; 78: 5403-5411

54 Dingle CT, Butler-Wu SM. MALDI-TOF mass spectrometry for microorganism identification. Clin Lab Med 2013; 33: 589-609

55 Lai YH, So PK, Lo SCL, Ng EWY, Poon TCW, Yao ZP. Rapid differentiation of Panax ginseng and Panax quinquefolius by matrix-assisted laser desorption/ionization mass spectrometry. Anal Chim Acta 2012; 753: 73-81

56 Wu $W$, Liang Z, Zhao Z, Cai Z. Direct analysis of alkaloid profiling in plant tissue by using matrix-assisted laser desorption/ionization mass spectrometry. J Mass Spectrom 2007; 42: 58-69

57 Wang J, van der Heijden R, Spijksma G, Reijmers T, Wang M, Xu G, Hankemeier T, van der Greef J. Alkaloid profiling of the Chinese herbal medicine Fuzi by combination of matrix-assisted laser desorption ionization mass spectrometry with liquid chromatography-mass spectrometry. J Chromatogr A 2009; 1216: 2169-2178

58 Wu W, Qiao C, Liang Z, Xu H, Zhao Z, Cai Z. Alkaloid profiling in crude and processed Strychnos nux-vomica seeds by matrix-assisted laser desorption/ionization-time of flight mass spectrometry. J Pharm Biomed Anal 2007; 45: 430-436

59 Zhu F, Cai YZ, Xing J, Ke J, Zhan Z, Corke H. Rapid identification of gallotannins from Chinese galls by matrix-assisted laser desorption/ionization time-of-flight quadrupole ion trap mass spectrometry. Rapid Commun Mass Spectrom 2009; 23: 1678-1682

$60 \mathrm{Ng} \mathrm{KM}$, Liang Z, Lu W, Tang HW, Zhao Z, Che CM, Cheng YC. In vivo analysis and spatial profiling of phytochemicals in herbal tissue by matrixassisted laser desorption/ionization mass spectrometry. Anal Chem 2007; 79: 2745-2755

61 Greene LA, Isaac I, Gray DE, Schwartz SA. Streamlining plant sample preparation: the use of high-throughput robotics to process Echinacea samples for biomarker profiling by MALDI-TOF mass spectrometry. J Biomol Tech 2007; 18: 238-244

62 Musharraf SG, Ali A, Choudhary MI, Atta-ur-Rahman. Probing of metabolites in finely powdered plant material by direct laser desorption ionization mass spectrometry. J Am Soc Mass Spectrom 2014; 25: 530 537

63 Catharino RR, Marques LA, Santos LS, Baptista AS, Glória EM, CaloriDomingues MA, Facco EMP, Eberlin MN. Aflatoxin screening by MALDITOF mass spectrometry. Anal Chem 2005; 77: 8155-8157

64 Fraser PD, Enfissi EM, Goodfellow M, Eguchi T, Bramley PM. Metabolite profiling of plant carotenoids using the matrix-assisted laser desorption ionization time-of-flight mass spectrometry. Plant J 2007; 49: 552-564

65 Jerez M, Sineiro J, Guitián E, Núnez MJ. Identification of polymeric procyanidins from pine bark by mass spectrometry. Rapid Commun Mass Spectrom 2009; 23: 4013-4018

66 Behrens A, Maie N, Knicker H, Kögel-Knabner I. MALDI-TOF mass spectrometry and PSD fragmentation as means for the analysis of condensed tannins in plant leaves and needles. Phytochemistry 2003; 62: $1159-1170$

67 Jones JJ, Stump MJ, Fleming RC, Lay jr. JO, Wilkins CL. Strategies and data analysis techniques for lipid and phospholipid chemistry elucidation by intact cell MALDI-FTMS. J Am Soc Mass Spectrom 2004; 15: 16651674

68 Wang J, Sporns P. MALDI-TOF MS analysis of food flavonol glycosides. J Agric Food Chem 2000; 48: 1657-1662 
69 Svatoš A. Single-cell metabolomics comes of age: new developments in mass spectrometry profiling and imaging. Anal Chem 2011; 83: 50375044

70 Kueger S, Steinhauser D, Willmitzer L, Giavalisco P. High-resolution plant metabolomics: from mass spectral features to metabolites and from whole-cell analysis to subcellular metabolite distributions. Plant J 2012; 70: 39-50

71 Hegeman $A D$. Plant metabolomics-meeting the analytical challenges of comprehensive metabolite analysis. Brief Funct Genomics 2010; 9: 139-148

72 Shroff R, Rulišek L, Doubský J, Svatoš A. Acid-base-driven matrix-assisted mass spectrometry for targeted metabolomics. Proc Natl Acad Sci U S A 2009; 106: 10092-10096

73 Kaspar S, Peukert M, Svatos A, Matros A, Mock HP. MALDI-imaging mass spectrometry - An emerging technique in plant biology. Proteomics 2011; $11: 1840-1850$

74 Silva DB, Turatti ICC, Gouveia DR, Ernst M, Teixeira SP, Lopes NP. Mass spectrometry of flavonoid vicenin-2, based sunlight barriers in Lychnophora species. Sci Rep 2014; 4: 4309

75 Lee YJ, Perdian DC, Song Z, Yeung ES, Nikolau BJ. Use of mass spectrometry for imaging metabolites in plants. Plant J 2012; 70: 81-95

76 Fuchs B, Süß R, Nimptsch A, Schiller J. MALDI-TOF-MS directly combined with TLC: a review of the current state. Chromatographia 2009; 69: S95-S105

77 Fuchs B, Schiller J, Süss R, Schürenberg M, Suckau D. A direct and simple method of coupling matrix-assisted laser desorption and ionization time-of-flight mass spectrometry (MALDI-TOF MS) to thin-layer chromatography (TLC) for the analysis of phospholipids from egg yolk. Anal Bioanal Chem 2007; 389: 827-834

78 Bonfill M, Mangas S, Cusidó RS, Osuna L, Piño MT, Palazón J. Identification of triterpenoid compounds of Centella asiatica by thin-layer chromatography and mass spectrometry. Biomed Chromatogr 2006; 20: 151-153

79 Hayen H, Volmer DA. Rapid identification of siderophores by combined thin-layer chromatography/matrix-assisted laser desorption/ionization mass spectrometry. Rapid Commun Mass Spectrom 2005; 19 : $711-720$

80 Shariatgorji M, Spacil Z, Maddalo G, Cardenas LB, Ilag LL. Matrix-free thin-layer chromatography/laser desorption ionization mass spectrometry for facile separation and identification of medicinal alkaloids. Rapid Commun Mass Spectrom 2009; 23: 3655-3660

81 Yamagaki T, Watanabe T. Hydrogen radical removal causes complex overlapping isotope patterns of aromatic carboxylic acids in negativeion matrix-assisted laser desorption/ionization mass spectrometry. Mass Spectrom (Tokyo) 2012; 1: A0005

82 Wang X, Han J, Chou A, Yang J, Pan J, Borchers $C H$. Hydroxyflavones as a new family of matrices for MALDI tissue imaging. Anal Chem 2013; 85: 7566-7573

83 Hvattum E, Ekeberg D. Study of the collision-induced radical cleavage of flavonoid glycosides using negative electrospray ionization tandem quadrupole mass spectrometry. J Mass Spectrom 2003; 38: 43-49

84 Houston CT, Taylor WP, Widlanski TS, Reilly JP. Investigation of enzyme kinetics using quench-flow techniques with MALDI-TOF mass spectrometry. Anal Chem 2000; 72: 3311-3319

85 Xu Z, Yao S, Wei Y, Zhou J, Zhang L, Wang C, Guo Y. Monitoring enzyme reaction and screening of inhibitors of acetylcholinesterase by quantitative matrix-assisted laser desorption/ionization fourier transform mass spectrometry. J Am Soc Mass Spectrom 2008; 19: 1849-1855

86 Su X, Kong L, Lei X, Hu L, Ye M, Zou H. Biological fingerprinting analysis of traditional Chinese medicines with targeting ADME/Tox property for screening of bioactive compounds by chromatographic and MS methods. Mini Rev Med Chem 2007; 7: 87-98

87 Pan C, Xu S, Hu L, Su X, Ou J, Zou H, Guo Z, Zhang Y, Guo B. Using oxidized carbon nanotubes as matrix for analysis of small molecules by MALDITOF MS. J Am Soc Mass Spectrom 2005; 16: 883-892

88 Xu SY, Li YF, Zou HF, Qiu JS, Guo Z, Guo BC. Carbon nanotubes as assisted matrix for laser desorption/ionization time-of-flight mass spectrometry. Anal Chem 2003; 75: 6191-6195

89 Ugarov MV, Egan T, Khabashesku DV, Schultz JA, Peng HQ Khabashesku VN, Furutani H, Prather KS, Wang HWJ, Jackson SN, Woods AS. MALDI matrices for biomolecular analysis based on functionalized carbon nanomaterials. Anal Chem 2004; 76: 6734-6742

90 Fisher AA, Labenski MT, Monks TJ, Lau SS. Utilization of MALDI-TOF to determine chemical-protein adduct formation in vitro. Methods Mol Biol 2011; 691: 303-316
91 Mané C, Sommerer N, Yalcin T, Cheynier V, Cole RB, Fulcrand H. Assessment of the molecular weight distribution of tannin fractions through MALDI-TOF MS analysis of protein-tannin complexes. Anal Chem 2007; 79: 2239-2248

92 Chen $Y$, Hagerman AE. Characterization of soluble non-covalent complexes between bovine serum albumin and $\beta$-1, 2, 3, 4, 6-penta$O$-galloyl-D-glucopyranose by MALDI-TOF MS. J Agric Food Chem 2004; 52: 4008-4011

93 Xu S, Pan C, Hu L, Zhang Y, Guo Z, Li X, Zou H. Enzymatic reaction of the immobilized enzyme on porous silicon studied by matrix-assisted laser desorption/ionization-time of flight-mass spectrometry. Electrophoresis 2004; 25: 3669-3676

94 Caprioli RM, Farme TB, Gile J. Molecular imaging of biological sample$\mathrm{s}$ : localization of peptides and proteins using MALDI-TOF MS. Anal Chem 1997; 69: 4751-4760

95 Schwamborn K, Caprioli RM. Molecular imaging by mass spectrometry - looking beyond classical histology. Nat Rev Cancer 2010; 10: 639646

96 Balluff B, Schöne C, Höfler H, Walch A. MALDI imaging mass spectrometry for direct tissue analysis: technological advancements and recent applications. Histochem Cell Biol 2011; 136: 227-244

97 Watrous JD, Alexandrov T, Dorrestein PC. The evolving field of imaging mass spectrometry and its impact on future biological research. J Mass Spectrom 2011; 46: 209-222

98 Nunes TM, Mateus S, Favaris AP, Amaral MF, Zuben LG, Clososki GC, Bento JMS, Oldroyd BP, Silva R, Zucchi R, Silva DB, Lopes NP. Queen signals in a stingless bee: suppression of worker ovary activation and spatial distribution of active compounds. Sci Rep 2014; 4: 7449

99 Andersson M, Andren P, Caprioli RM. MALDI imaging and profiling mass spectrometry in neuroproteomics. In: Aalzate O, editor. Neuroproteomics. Boca Raton, FL: CRC Press/Taylor \& Francis; 2010: $115-134$

100 Dong Y, Li B, Malitsky S, Rogachev I, Aharoni A, Kaftan F, Svatoš A, Franceschi $P$. Sample preparation for mass spectrometry imaging of plant tissues: a review. Front Plant Sci 2016; 7: 60

101 Burrell M, Earnshaw C, Clench M. Imaging matrix assisted laser desorption ionization mass spectrometry: a technique to map plant metabolites within tissues at high spatial resolution. J Exp Bot 2007; 58: 757-763

102 Esquenazi E, Yang YL, Watrous J, Gerwick WH, Dorrestein PC. Imaging mass spectrometry of natural products. Nat Prod Rep 2009; 26: 1521-1534

103 Watrous JD, Dorrestein PC. Imaging mass spectrometry in microbiology. Nat Rev Microbiol 2011; 9: 683-694

104 Moree WJ, Phelan VV, Wu CH, Bandeira N, Cornett DS, Duggan BM, Dorrestein PC. Interkingdom metabolic transformations captured by microbial imaging mass spectrometry. Proc Natl Acad Sci U S A 2012; 109: 13811-13816

105 Handberg E, Chingin K, Wang N, Dai X, Chen H. Mass spectrometry imaging for visualizing organic analytes in food. Mass Spectrom Rev 2015; 34: 641-658

106 Shroff R, Vergara F, Muck A, Svatoš A, Gershenzon J. Nonuniform distribution of glucosinolates in Arabidopsis thaliana leaves has important consequences for plant defense. Proc Natl Acad Sci U S A 2008; 105 : 6196-6201

107 Hölscher D, Shroff R, Knop K, Gottschaldt M, Crecelius A, Schneider B, Heckel DG, Schubert US, Svatos A. Matrix-free UV-laser desorption/ ionization (LDI) mass spectrometric imaging at the single-cell level: distribution of secondary metabolites of Arabidopsis thaliana and Hypericum species. Plant J 2009; 60: 907-918

108 Franceschi P, Dong Y, Strupat K, Vrhovsek U, Mattivi F. Combining intensity correlation analysis and MALDI imaging to study the distribution of flavonols and dihydrochalcones in Golden Delicious apples. J Exp Bot 2012; 63: 1123-1133

109 Goto-Inoue N, Setou M, Zaima N. Visualization of spatial distribution of gamma-aminobutyric acid in eggplant (Solanum Melongena) by matrix-assisted laser desorption/ionization imaging mass spectrometry. Anal Sci 2010; 26: 821-825

110 Goodwin RJ. Sample preparation for mass spectrometry imaging: small mistakes can lead to big consequences. J Proteomics 2012; 75: 4893-4911

111 Peukert M, Matros A, Lattanzio G, Kaspar S, Abadía J, Mock HP. Spatially resolved analysis of small molecules by matrix-assisted laser desorption/ionization mass spectrometric imaging (MALDI-MSI). New Phytol 2012; 193 : 806-815 
112 Prentice BM, Chumbley CW, Caprioli RM. High-speed MALDI MS/MS imaging mass spectrometry using continuous raster sampling. J Mass Spectrom 2015; 50: 703-710

113 McDonnell LA, Römpp A, Balluff B, Heeren RMA, Albar JP, Andrén PE, Corthals GL, Walch A, Stoeckli M. Discussion point: reporting guidelines for mass spectrometry imaging. Anal Bioanal Chem 2015; 407: 2035-2045

114 Thiele H, Heldmann S, Trede D, Strehlow J, Wirtz S, Dreher W, Berger J, Oetjen J, Kobarg JH, Fischer B, Maass P. 2D and 3D MALDI-imaging: conceptual strategies for visualization and data mining. Biochim Biophys Acta 2014; 1844: 117-137

115 Heeren RMA. Getting the picture: The coming of age of imaging MS. Int J Mass Spectrom 2015; 377: 672-680

116 Heyman HM, Dubery IA. The potential of mass spectrometry imaging in plant metabolomics: a review. Phytochem Rev 2016; 15: 297-316

117 Horn PJ, Chapman KD. Lipidomics in situ: insights into plant lipid metabolism from high resolution spatial maps of metabolites. Prog Lipid Res 2014; 54: 32-52

118 Dalisay DS, Kim KW, Lee C, Yang H, Rübel O, Bowen BP, Davin LB, Lewis NJ. Dirigent protein-mediated lignan and cyanogenic glucoside formation in flax seed: integrated omics and MALDI mass spectrometry imaging. J Nat Prod 2015; 78: 1231-1242

119 Cotter RJ. Time-of-flight mass spectrometer. In: Cole RB, editor. Electrospray and MALDI mass spectrometry: fundamentals, instrumentation, practicalities, and biological applications. Hoboken: John Wiley \& Sons; 2010: 345-364

120 Wolff JJ, Amster IJ. Fourier transform ion cyclotron resonance and magnetic sector analyzers for ESI and MALDI. In: Cole RB, editor. Electrospray and MALDI mass spectrometry: fundamentals, instrumentation, practicalities, and biological applications. Hoboken: John Wiley \& Sons; 2010: 365-406

121 Hakansson K, Klassen JS. Ion activation methods for tandem mass spectrometry. In: Cole RB, editor. Electrospray and MALDI mass spectrometry: fundamentals, instrumentation, practicalities, and biological applications. Hoboken: John Wiley \& Sons; 2010: 571-630

122 March RE, Li H, Belgacem O, Papanastasiou D. High-energy and lowenergy collision-induced dissociation of protonated flavonoids generated by MALDI and by electrospray ionization. Int J Mass Spectrom 2007; 262: 51-66

123 Zhou X, Wei Y, He Q Boey F, Zhang Q Zhang H. Reduced graphene oxide films used asmatrix of MALDI-TOF-MS for detection of octachlorodibenzo-p-dioxin. Chem Commun (Camb) 2010; 46: 6974-6976

124 Madeira PJA, Florêncio MH. Flavonoid-matrix cluster ions in MALDI mass spectrometry. J Mass Spectrom 2009; 44: 1105-1113

125 Yamagaki T, Watanabe T, Tanaka M, Sugahara K. Laser-Induced hydrogen radical removal in UV MALDI MS allows for the differentiation of flavonoid monoglycoside isomers. J Am Soc Mass Spectrom 2014; 25: 88-94

126 Pavarini DP, Silva DB, Carollo CA, Portella APF, Latansio-Aidar SR, Cavalin PO, Oliveira VC, Rosado BHP, Aidar MPM, Bolzani VS, Lopes NP, Joly CA. Application of MALDI-MS analysis of rainforest chemodiversity: a keystone for biodiversity conservation and sustainable use. J Mass Spectrom 2012; 47: 1482-1485

127 March RE, Lewars EG, Stadey CJ, Miao XS, Zhao X, Metcalfe CD. A comparison of flavonoid glycosides by electrospray tandem mass spectrometry. Int J Mass Spectrom 2006; 248: 61-85

128 Radebe N, Rode K, Pizzi A, Pasch H. Microstructure elucidation of polyflavonoid tannins by MALDI-TOF-CID. J Appl Polym Sci 2012; 127: $1937-1950$

129 Moneti G, Francese S, Mastrobuoni G, Pieraccini G, Seraglia R, Valitutti $G$, Traldi P. Do collisions inside the collision cell play a relevant role in CID-LIFT experiments? J Mass Spectrom 2007; 42: 117-126

130 Neubert H, Halket JM, Ocana MF, Patel RKP. MALDI post-source decay and LIFT-TOF/TOF investigation of $\alpha$-cyano-4-hydroxycinnamic acid cluster interferences. J Am Soc Mass Spectrom 2004; 15: 336-343

131 Jespersen S, Chaurand P, van Strien FJ, Spengler B, van der GreefJ. Direct sequencing of neuropeptides in biological tissue by MALDI-PSD mass spectrometry. Anal Chem 1999; 71: 660-666

132 Spengler B. Post-source decay analysis in matrix-assisted laser desorption/ionization mass spectrometry of biomolecules. J Mass Spectrom 1997; 32: 1019-1036

133 Talbo G, Mann M. Aspects of the sequencing of carbohydrates and oligonucleotides by matrix-assisted laser desorption/ionization postsource decay. Rapid Commun Mass Spectrom 1996; 10: 100-103
134 Zehl M, Pittenauer E, Jirovetz L, Bandhari P, Singh B, Kaul VK, Rizzi AR, Allmaier $G$. Multistage and tandem mass spectrometry of glycosylated triterpenoid saponins isolated from Bacopa monnieri: comparison of the information content provided by different techniques. Anal Chem 2007; 79: 8214-8221

135 Wang J, Sporns P. MALDI-TOF MS analysis of isoflavones in soy products. J Agric Food Chem 2000; 48: 5887-5892

136 Wingerath T, Stahl W, Kirsch D, Kaufmann R, Sies H. Fruit juice carotenol fatty acid esters and carotenoids as identified by matrix-assisted laser desorption ionization (MALDI) mass spectrometry. J Agric Food Chem 1996; 44: 2006-2013

137 Radebe N, Rode K, Pizzi A, Giovando S, Pasch H. MALDI-TOF-CID for the microstructure elucidation of polymeric hydrolysable tannins. J Appl Polym Sci 2013; 128: 97-107

138 Fuchs B, Schober C, Richter G, Süss R, Schiller J. MALDI-TOF MS of phosphatidylethanolamines: different adducts cause different post source decay (PSD) fragment ion spectra. J Biochem Biophys Methods 2007; 70: 689-692

139 Picariello G, Sacchi R, Addeo F. One-step characterization of triacylglycerols from animal fat by MALDI-TOF MS. Eur J Lipid Sci Technol 2007 109: 511-524

140 Fuchs B, Süss R, Schiller J. An update of MALDI-TOF mass spectrometry in lipid research. Prog Lipid Res 2010; 49: 450-475

141 Guaratini T, Vessecchi R, Pinto E, Colepicolo P, Lopes NP. Balance of xanthophylls molecular and protonated molecular ions in electrospray ionization. J Mass Spectrom 2005; 40: 963-968

142 Vessecchi E, Crotti AE, Guaratini T, Colepicolo P, Galembeck SE, Lopes NP. Radical ion generation processes of organic compounds in electrospray ionization mass spectrometry. Mini Rev Org Chem 2007; 4 $75-87$

143 van Breemen RB, Schmitz HH, Schwartz SJ. Fast atom bombardment tandem mass spectrometry of carotenoids. J Agric Food Chem 1995; 43: 384-389

144 Kéki S, Deák G, Lévai A, Zsuga M. Post-source decay matrix-assisted laser desorption/ionization mass spectrometric study of peracetylated isoflavone glycosides cationized by protonation and with various metal ions. J Mass Spectrom 2003; 38: 1207-1209

145 Kéki S, Nagy L, Deák G, Zsuga M, Somogyi L, Lévai A. Cationization of simple organic molecules by singly-charged $\mathrm{Ag}_{3}{ }^{+}$cluster ions in matrix-assisted laser desorption/ionization mass spectrometry: metal cluster-molecule interactions. J Am Soc Mass Spectrom 2004; 15: 879-883

146 Guo S, Falk E, Kenne L, Rönnberg B, Sundquist BG. Triterpenoid saponins containing an acetylated branched D-fucosyl residue from Quillaja saponaria Molina. Phytochemistry 2000; 53: 861-868

147 Dyck SV, Gerbaux P, Flammang P. Elucidation of molecular diversity and body distribution of saponins in the sea cucumber Holothuria forskali (Echinodermata) by mass spectrometry. Comp Biochem Physiol B Biochem Mol Biol 2009; 152: 124-134

148 Cheng C, Gross ML. Applications and mechanisms of charge-remote fragmentation. Mass Spectrom Rev 2000; 19: 398-420

149 Griffiths $W$. Tandem mass spectrometry in the study of fatty acids, bile acids, and steroids. Mass Spectrom Rev 2003; 22: 81-152

150 Bahrami Y, Zhang W, Chataway T, Franco C. Structural elucidation of novel saponins in the sea cucumber Holothuria lessoni. Mar Drugs 2014; 12: 4439-4473

151 Bahrami Y, Zhang W, Franco C. Discovery of novel saponins from the viscera of the sea cucumber Holothuria lessoni. Mar Drugs 2014; 12 : 2633-2667

152 Pasch H, Pizzi A, Rode K. MALDI-TOF mass spectrometry of polyflavonoid tannins. Polymer (Guildf) 2001; 42: 7531-7539

153 Guaratini T, Armelini AI, Ferrari CR, Schefer RR, Neto AP, Navas $R$ Reigada JB, Silva DB. Application of matrix-assisted laser-desorption/ ionization time-of-flight LIFT for identification of cocoa condensed tannins. J Mass Spectrom 2014; 49: 251-255

154 Mateos-Martín ML, Fuguet E, Quero C, Pérez-Jiménez J, Torres JL. New identification of proanthocyanidins in cinnamon (Cinnamomum zeylanicum L.) using MALDI-TOF/TOF MS. Anal Bioanal Chem 2012; 402: $1327-1336$

155 Prado LC, Silva DB, de Oliveira-Silva GL, Hiraki KR, Canabrava HA Bispo-da-Silva LB. The gastroprotective effects of Eugenia dysenterica (Myrtaceae) leaf extract: the possible role of condensed tannins. Biol Pharm Bull 2014; 37: 722-730

156 Trentin DS, Silva DB, Amaral MW, Zimmer KR, Silva MV, Lopes NP, Giordani RB, Macedo AJ. Tannins possessing bacteriostatic effect im- 
pair Pseudomonas aeruginosa adhesion and biofilm formation. PLoS One 2013; 11: e66257

157 Trentin DS, Silva DB, Frasson AP, Rzhepishevska O, da Silva MV, Pulcini EL, James G, Soares GV, Tasca T, Ramstedt M, Giordani RB, Lopes NP, Macedo AJ. Natural Green coating inhibits adhesion of clinically important bacteria. Sci Rep 2015; 5: 8287

158 Pérez-Jiménez J, Torres JL. Analysis of proanthocyanidins in almond blanch water by HPLC-ESI-QqQ-MS/MS and MALDI-TOF/TOF MS. Food Res Int 2012; 49: 798-806

159 Cai YZ, Xing J, Sun M, Zhan ZK, Corke H. Phenolic antioxidants (hydrolyzable tannins, flavonols, and anthocyanins) identified by LC-ESI-MS and MALDI-QIT-TOF MS from Rosa chinensis flowers. J Agric Food Chem 2005; 53: 9940-9948

160 Sáyago-Ayerdi SG, Moreno-Hernández CL, Montalvo-González E, García-Magaña ML, Oca MMM, Torres JL, Pérez-Jiménez J. Mexican 'Ataulfo' mango (Mangifera indica $\mathrm{L}$ ) as a source of hydrolyzable tannins. Analysis by MALDI-TOF/TOF MS. Food Res Int 2013; 51: 188-194

161 Xiang $P$, Lin $Y$, Lin P, Xiang C, Yang $Z$, Lu Z. Effect of cationization reagents on the matrix-assisted laser desorption/ionization time-offlight mass spectrum of Chinese gallotannins. J Appl Polym Sci 2007; 105: 859-864

162 Silva VC, Napolitano A, Eletto D, Rodrigues CM, Pizza C, Vilegas W. Characterization of gallotannins from Astronium species by flow injection analysis- electrospray ionization-ion trap-tandem mass spectrometry and matrix-assisted laser desorption/ionization time-of- flight mass spectrometry. Eur J Mass Spectrom 2011; 17: 365-375

163 Reed JD, Krueger CG, Vestling MM. MALDI-TOF mass spectrometry of oligomeric food polyphenols. Phytochemistry 2005; 66: 2248-2263

164 Meyers KJ, Swiecki TJ, Mitchell AE. Understanding the native Californian diet: identification of condensed and hydrolyzable tannins in tanoak acorns (Lithocarpus densiflorus). J Agric Food Chem 2006; 54 : 7686-7691

165 Berardini $N$, Carle $R$, Schieber A. Characterization of gallotannins and benzophenone derivatives frommango (Mangifera indica L. cV. 'Tommy Atkins') peels, pulp and kernels by high-performance liquid chromatography/electrospray ionization mass spectrometry. Rapid Commun Mass Spectrom 2004; 18: 2208-2216

166 Spina E, Sturiale L, Romeo D, Impallomeni G, Garozzo D, Waidelich D, Glueckmann $M$. New fragmentation mechanisms in matrix-assisted laser desorption/ionization time-of-flight/time-of-flight tandem mass spectrometry of carbohydrates. Rapid Commun Mass Spectrom 2004; 18: 392-398

167 Harvey DJ. Matrix-assisted laser desorption/ionization mass spectrometry of carbohydrates. Mass Spectrom Rev 1999; 18: 349-451

168 Yoshimura Y, Zaima N, Moriyama T, Kawamura Y. Different localization patterns of anthocyanin species in the pericarp of black rice revealed by imaging mass spectrometry. PLoS One 2012; 7: e31285

169 Menet MC, Sang S, Yang CS, Ho CT, Rosen RT. Analysis of theaflavins and thearubigins from black tea extract by MALDI-TOF mass spectrometry. J Agric Food Chem 2004; 52: 2455-2461

170 Yassin $\mathrm{GH}$, Koek JH, Kuhnert N. Identification of trimeric and tetrameric flavan-3-ol derivatives in the SII black tea thearubigin fraction of black tea using ESI-tandem and MALDI-TOF mass spectrometry. Food Res Int 2014; 63: 317-327

171 Ho YC, Tseng MC, Lu YW, Lin CC, Chen YJ, Fuh MR. Nanoparticle-assisted MALDI-TOF MS combined with seed layer surface preparation for quantification of small molecules. Anal Chim Acta 2011; 697: 1-7

172 Pham TV, Jimenez CR. OplAnalyzer: a toolbox for MALDI-TOF mass spectrometry data analysis. In: Perner P, Salvetti O, editors. Advances in mass data analysis of images and signals in medicine, biotechnology, chemistry and food industry, 3rd edition. Leipzig, Germany: Springer; 2008: 73-81

173 Kumar C, Mann M. Bioinformatics analysis of mass spectrometrybased proteomics data sets. FEBS Lett 2009; 583: 1703-1712

174 Alexandrov T. MALDI imaging mass spectrometry: statistical data analysis and current computational challenges. BMC Bioinformatics 2012; 13: S11

175 Morris JS, Baggerly KA, Gutstein HB, Coombes KR. Statistical contributions to proteomic research. Methods Mol Biol 2010; 641: 143-166

176 Ge G, Wong GW. Classification of premalignant pancreatic cancer mass-spectrometry data using decision tree ensembles. BMC Bioinformatics 2008; 9: 275

177 Tong DL, Boocock DJ, Coveney C, Saif J, Gomez SG, Querol S, Rees R, Ball $G R$. A simpler method of preprocessing MALDI-TOF MS data for differ- ential biomarker analysis: stem cell and melanoma cancer studies. Clin Proteomics 2011; 8: 14

178 Ressom HW, Varghese RS, Goldman L, Loffredo CA, Abdel-Hamid M Kyselova Z, Mechref Y, Novotny M, Goldman R. Analysis of MALDI-TOF mass spectrometry data for detection of glycan biomarkers. Pac Symp Biocomput 2008; 216-227

179 Oberg AL, Vitek 0 . Statistical design of quantitative mass spectrometry-based proteomic experiments. J Proteome Res 2009; 8: $2144-$ 2156

$180 \mathrm{Hu}$ J, Coombes KR, Morris JS, Baggerly KA. The importance of experimental design in proteomic mass spectrometry experiments: some cautionary tales. Brief Funct Genomic Proteomic 2005; 3: 322-331

181 Cairns DA. Statistical issues in quality control of proteomic analyses: good experimental design and planning. Proteomics 2011; 11: 1037-1048

182 Zhang L, Borror CM, Sandrin TR. A designed experiments approach to optimization of automated data acquisition during characterization of bacteria with MALDI-TOF mass spectrometry. PLoS One 2014; 9: e92720

183 Xiang B, Prado $M$. An accurate and clean calibration method for MALDI-MS. J Biomol Tech 2010; 21: 116-119

184 Saideman SR, Ma M, Kutz-Naber KK, Cook A, Torfs P, Schoofs L, Li L, Nusbaum MP. Modulation of rhythmic motor activity by pyrokinin peptides. J Neurophysiol 2007; 97: 579-595

$185 \mathrm{He} \mathrm{Z,} \mathrm{Qi} \mathrm{RZ,} \mathrm{Yu} \mathrm{W.} \mathrm{Bioinformatic} \mathrm{analysis} \mathrm{of} \mathrm{data} \mathrm{generated} \mathrm{from}$ MALDI mass spectrometry for biomarker discovery. Top Curr Chem 2013; 331: 193-209

186 Hilario M, Kalousis A. Approaches to dimensionality reduction in proteomic biomarker studies. Brief Bioinform 2008; 9: 102-118

187 Hilario M, Kalousis A, Pellegrini C, Müller M. Processing and classification of protein mass spectra. Mass Spectrom Rev 2006; 25: 409-449

188 Gibb S, Strimmer K. MALDIquant: a versatile R package for the analysis of mass spectrometry data. Bioinformatics 2012; 28: 2270-2271

189 Ryan CG, Clayton E, Griffin WL, Sie SH, Cousens DR. SNIP, a statisticssensitive background treatment for the quantitative analysis of PIXE spectra in geoscience applications. Nucl Instrum Methods Phys Res B 1988; 34: 396-402

190 Veltri P. Algorithms and tools for analysis and management of mass spectrometry data. Brief Bioinform 2008; 9: 144-155

191 He QP, Wang J, Mobley JA, Richman J, Grizzle WE. Self-calibrated warping for mass spectra alignment. Cancer Inform 2011; 10: 65-82

192 Bloemberg TG, Gerretzen J, Lunshof A, Wehrens R, Buydens LMC. Warping methods for spectroscopic and chromatographic signal alignment: a tutorial. Anal Chim Acta 2013; 781: 14-32

193 R Development Core Team. R: A language and environment for statistical computing. Vienna, Austria: R Foundation for Statistical Computing; 2010

194 Yang C, He Z, Yu W. Comparison of public peak detection algorithms for MALDI mass spectrometry data analysis. BMC Bioinformatics 2009; $10: 4$

195 Smith CA, Want EJ, O'Maille G, Abagyan R, Siuzdak G. XCMS: processing mass spectrometry data for metabolite profiling using nonlinear peak alignment, matching, and identification. Anal Chem 2006; 78: 779787

196 Wang W, Zhou H, Lin H, Roy S, Shaler TA, Hill LR, Norton S, Kumar P, Anderle $M$, Becker $\mathrm{CH}$. Quantification of proteins and metabolites by mass spectrometry without isotopic labeling or spiked standards. Anal Chem 2003; 75: 4818-4826

197 Ejigu BA, Valkenborg D, Baggerman G, Vanaerschot M, Witters E, Dujardin JC, Burzykowski T, Berg M. Evaluation of normalization methods to pave the way towards large-scale LC-MS-based metabolomics profiling experiments. OMICS 2013; 17: 473-485

198 Deininger SO, Cornett DS, Paape R, Becker M, Pineau C, Rauser S, Walch A, Wolski E. Normalization in MALDI-TOF imaging datasets of proteins: practical considerations. Anal Bioanal Chem 2011; 401: 167181

199 Webb A. Statistical pattern recognition. New York: Oxford University Press; 1999

200 Suzuki R, Shimodaira H. Pvclust: an R package for assessing the uncertainty in hierarchical clustering. Bioinformatics 2006; 22: 1540-1542

201 Wehrens $R$. Chemometrics with R: multivariate data analysis in the natural sciences and life sciences (Use R!). New York: Springer; 2011

202 Alexandrov T, Kobarg JH. Efficient spatial segmentation of large imaging mass spectrometry datasets with spatially aware clustering. Bioinformatics 2011; 27: i230-i238 
203 Giacomoni F, Le Corguillé G, Monsoor M, Landi M, Pericard P, Pétéra M, Duperier C, Tremblay-Franco M, Martin JF, Jacob D, Goulitquer S, Thévenot EA, Caron C. Workflow4Metabolomics: a collaborative research infrastructure for computational metabolomics. Bioinformatics 2015; 31: 1493-1495

204 Steinbeck C, Conesa P, Haug K, Mahendraker T, Williams M, Maguire E, Rocca-Serra P, Sansone SA, Salek RM, Griffin JL. MetaboLights: towards a new COSMOS of metabolomics data management. Metabolomics 2012; 8: 757-760

205 Ara T, Enomoto M, Arita M, Ikeda C, Kera K, Yamada M, Nishioka T, Ikeda T, Nihei Y, Shibata D, Kanaya S, Sakurai N. Metabolonote: a wiki-based database for managing hierarchical metadata of metabolome analyses. Front Bioeng Biotechnol 2015; 3: 38

206 Aamodt A, Plaza E. Case-based reasoning: foundational issues, methodological variations, and system approaches. AI communications 1994; 7: 39-59

207 Forim MR, Cornélio VE, da Silva MF, Rodrigues-Filho E, Fernandes JB, Vieira PC, Matinez SS, Napolitano MP, Yost RA. Chemical characterization of Azadirachta indica grafted on Melia azedarach and analyses of azadirachtin by HPLC-MS-MS (SRM) and meliatoxins by MALDI-MS. Phytochem Anal 2010; 21: 363-373

208 Pogam PL, Schinkovitz A, Legouin B, Lamer ACL, Boustie L, Richomme P. Matrix-free UV-laser desorption ionization mass spectrometry as a versatile approach for accelerating dereplication studies on lichens. Anal Chem 2015; 87: 10421-10428

209 Wang H, Dai B, Liu B, Lu H. Coumarins as new matrices for matrix-assisted laser-desorption/ionization Fourier transform ion cyclotron resonance mass spectrometric analysis of hydrophobic compounds. Anal Chim Acta 2015; 882: 49-57

210 Annangudi SP, Myung K, Adame CA, Gilbert JR. MALDI-MS imaging analysis of fungicide residue distributions on wheat leaf surfaces. Environ Sci Technol 2015; 49: 5579-5583

211 Berisha A, Dold S, Guenther S, Desbenoit N, Takats Z, Spengler B, Römpp $A$. A comprehensive high-resolution mass spectrometry approach for characterization of metabolites by combination of ambient ionization, chromatography and imaging methods. Rapid Commun Mass Spectrom 2014; 28: 1779-1791

212 Sekuła J, Nizioł J, Misiorek M, Dec P, Wrona A, Arendowski A, Ruman T. Gold nanoparticle-enhanced target for MS analysis and imaging of harmful compounds in plant, animal tissue and on fingerprint. Anal Chim Acta 2015; 895: 45-53

213 Shroff R, Schramm K, Jeschke V, Nemes P, Vertes A, Gershenzon J, Svatoš $A$. Quantification of plant surface metabolites by MALDI mass spectrometry imaging: glucosinolates on Arabidopsis thaliana leaves. Plant J 2015; 81: 961-972

214 Takahashi K, Kozuka T, Anegawa A, Nagatani A, Mimura T. Development and application of a high-resolution imaging mass spectrometer for the study of plant tissues. Plant Cell Physiol 2015; 56: 13291338

215 Oliveira DN, Ferreira MS, Catharino RR. Rapid and simultaneous in situ assessment of aflatoxins and stilbenes using silica plate imprinting mass spectrometry imaging. PLoS One 2014; 9: e90901

216 Gamboa-Becerra R, Ramírez-Chávez E, Molina-Torres J, Winkler R. MSI. $\mathrm{R}$ scripts reveal volatile and semi-volatile features in low-temperature plasma mass spectrometry imaging (LTP-MSI) of chilli (Capsicum annuum). Anal Bioanal Chem 2015; 407: 5673-5684

217 Soares MS, da Silva DF, Forim MR, da Silva MF, Fernandes JB, Vieira PC, Silva DB, Lopes NP, de Carvalho SA, de Souza AA, Machado MA. Quantification and localization of hesperidin and rutin in Citrus sinensis grafted on C. limonia after Xylella fastidiosa infection by HPLC-UV and MALDI imaging mass spectrometry. Phytochemistry 2015; 115 : $161-170$

218 Araújo P, Ferreira MS, de Oliveira DN, Pereira L, Sawaya AC, Catharino RR, Mazzafera P. Mass spectrometry imaging: an expeditious and powerful technique for fast in situ lignin assessment in Eucalyptus. Anal Chem 2014; 86: 3415-3419

219 Li B, Bhandari DR, Janfelt C, Römpp A, Spengler B. Natural products in Glycyrrhiza glabra (licorice) rhizome imaged at the cellular level by atmospheric pressure matrix-assisted laser desorption/ionization tandem mass spectrometry imaging. Plant J 2014; 80: 161-171

220 Horn PJ, Chapman KD. Metabolite Imager: customized spatial analysis of metabolite distributions in mass spectrometry imaging. Metabolomics 2014; 10: 337-348

221 Liaimer A, Helfrich EJN, Hinrichs K, Guljamow A, Ishida K, Hertweck C, Dittmann $E$. Nostopeptolide plays a governing role during cellular differentiation of the symbiotic cyanobacterium Nostoc punctiforme. Proc Natl Acad Sci U S A 2015; 112: 1862-1867

222 Peukert M, Thiel J, Peshev D, Weschke W, Van den Ende W, Mock HP, Matros A. Spatio-temporal dynamics of fructan metabolism in developing barley grains. Plant Cell 2014; 26: 3728-3744

223 Kusari S, Sezgin S, Nigutova K, Cellarova E, Spiteller M. Spatial chemoprofiling of hypericin and related phytochemicals in Hypericum species using MALDI-HRMS imaging. Anal Bioanal Chem 2015; 407: 4779-4791

224 Rudolph-Mohr N, Gottfried S, Lamshöft M, Zühlke S, Oswald SE, Spiteller $M$. Non-invasive imaging techniques to study $\mathrm{O}_{2}$ micro-patterns around pesticide treated lupine roots. Geoderma 2015; 239-240: 257-264

225 Gemperline E, Jayaraman D, Maeda J, Ané JM, Li L. Multifaceted investigation of metabolites during nitrogen fixation in medicago via high resolution MALDI-MS imaging and ESI-MS. J Am Soc Mass Spectrom 2015; 26: 149-158

226 Holscher D, Fuchser J, Knop K, Menezes RC, Buerkert A, Svatoš A, Schubert US, Schneider $B$. High resolution mass spectrometry imaging reveals the occurrence of phenylphenalenone-type compounds in red paracytic stomata and red epidermis tissue of Musa acuminata ssp. zebrina cv. 'Rowe Red'. Phytochemistry 2015; 116: 239-245

227 Seneviratne HK, Dalisay DS, Kim KW, Moinuddin SGA, Yang H, Hartshorn CM, Davin LB, Lewis NG. Non-host disease resistance response in pea (Pisum sativum) pods: Biochemical function of DRR206 and phytoalexin pathway localization. Phytochemistry 2015; 113: 140 148

228 Seaman C, Flinders B, Eijkel G, Heeren RMA, Bricklebank N, Clenc MR. "Afterlife Experiment": use of MALDI-MS and SIMS imaging for the study of the nitrogen cycle within plants. Anal Chem 2014; 86: 10071-10077

229 Li C, Wang Z, Jones AD. Chemical imaging of trichome specialized metabolites using contact printing and laser desorption/ionization mass spectrometry. Anal Bioanal Chem 2014; 406: 171-182

230 Friesen WL, Schultz BJ, Destino JF, Alivio TEG, Steet JR, Banerjee S, Wood $T D$. Two-dimensional graphene as a matrix for MALDI imaging mass spectrometry. J Am Soc Mass Spectrom 2015; 26: 1963-1966

231 Velickovic D, Herdier H, Philippe G, Marion D, Rogniaux H, Bakan B. Matrix-assisted laser desorption/ionization mass spectrometry imaging: a powerful tool for probing the molecular topology of plant cutin polymer. Plant J 2014; 80: 926-935

232 Korte AR, Yandeau-Nelson MD, Nikolau BJ, Lee YJ. Subcellular-level resolution MALDI-MS imaging of maize leaf metabolites by MALDI-linear ion trap-Orbitrap mass spectrometer. Anal Bioanal Chem 2015; 407: 2301-2309 